Estudios Constitucionales, Año 12, No 1, 2014, pp. 285-328.

ISSN 07180195

Centro de Estudios Constitucionales de Chile Universidad de Talca

"Derechos Fundamentales Económicos y Sociales y la responsabilidad del Estado por omisión" Daniel Wunder Hachem

\title{
DERECHOS FUNDAMENTALES ECONÓMICOS Y SOCIALES Y LA RESPONSABILIDAD DEL ESTADO POR OMISIÓN*
}

\author{
FUNDAMENTAL ECONOMIC AND SOCIAL RIGHTS AND THE \\ STATE'S LIABILITY FOR OMISSION
}

\author{
Daniel Wunder Hachem** \\ Universidad Federal de Paraná - Brasil \\ danielhachem@gmail.com
}

RESUMEN: El objetivo de esta investigación es analizar qué se puede exigir directamente de la Administración Pública en materia de derechos económicos y sociales, y cuáles son los requisitos jurídicos exigibles para responsabilizar al Estado por omisión desde la Constitución brasileña actual. Se defiende en el trabajo que dicha exigibilidad no está limitada a las condiciones minimas de existencia digna y que, desde la concepción de multifuncionalidad inherente a todos los derechos fundamentales, la aplicabilidad inmediata de los llamados "derechos de libertad" y de los "derechos económicos y sociales" es la misma. Se sostiene, además, que para la configuración del deber estatal de indemnizar daños decurrentes de omisiones en este campo es innecesaria la perquisición de culpa, tratándose de hipótesis de responsabilidad objetiva.

ABSTRACT: The objective of this research is to analyze what can be directly demanded from Public Administration on economic and social rights, and what are the legal requirements to make the State responsible for the damages in the current Brazilian Constitution. It is defended in this paper that such enforcement is not limited to the minimum conditions to a decent life, and, from the conception of multifunctionality inherent in all fundamental rights, the immediate applicability of so-called "freedoms" and "economic and social rights" is the same. It also asserts that to configure the State's duty to indemnify damages resulting from omissions in this field, it is unnecessary to seek guilt, because it is a hypothesis of objective liability.

Palabras CLAVE: Derechos fundamentales, Derechos económicos y sociales, Responsabilidad del Estado, Omisión administrativa, Inactividad administrativa, Faute du service.

KEY WORDS: Fundamental rights, Economic and social rights, State's liability, Administrative omission, Administrative inactivity. Faute du service.

\footnotetext{
* Trabajo recibido el 18 de septiembre de 2013 y aprobado el 8 de enero de 2014.

** Profesor del Departamento de Derecho Público de la Universidad Federal de Paraná (Brasil). Doctor y Magíster en Derecho del Estado en la Universidad Federal de Paraná. Coordinador y Profesor de la Carrera de Posgrado (Especialización) en Derecho Administrativo del Instituto de Derecho Romeu Felipe Bacellar. Coordinador Ejecutivo, por Brasil, de la Red Docente Eurolatinoamericana de Derecho Administrativo. Miembro del NINC - Núcleo de Investigaciones Constitucionales de la Universidad Federal de Paraná. Editor Académico de la $A \& C$ - Revista de Derecho Administrativo \& Constitucional. Abogado en Brasil.
} 


\section{INTRODUCCIÓN}

El día 17 de septiembre de 2011 fue publicada en el jornal Zero Hora, en Brasil, una noticia informando que, después de 17 días esperando en la cola, se murió en el municipio de Viamão - Rio Grande do Sul el señor Davi Oliveira Gonçalves, por falta de cama en Unidad de Terapia Intensiva de hospital público. La muerte ocurrió el sábado, y desde el martes ya había decisión judicial que obligaba al Estado a costear una cama en otra casa de salud. Una semana antes, ya se había muerto también una joven de 17 años, después de esperar 19 días por una transferencia en el mismo hospital. ${ }^{1}$

Dos meses antes, había sido publicada una noticia en el sitio de la red $R 7$, divulgando la muerte de Elba Luiza do Nascimento, de 27 años, después de 15 días de internamiento por ausencia de condiciones de atención en hospital público estadual en Rio de Janeiro. Por falta de médico neurólogo, fue transferida para otro hospital, que tampoco tenía médico especializado para atenderla, y por ello retornó. La joven quedó abandonada en el corredor de la unidad de salud y se murió dos días después. ${ }^{2}$

Estos casos - como tantos otros similares divulgados por la prensa brasileñaretratan un problema habitual de la Administración Pública latinoamericana: la omisión. No es sorprendente que uno de los más célebres personajes de las historietas en Latinoamérica -Mafalda, y también Felipe y Manolito- han llegado a la siguiente conclusión:
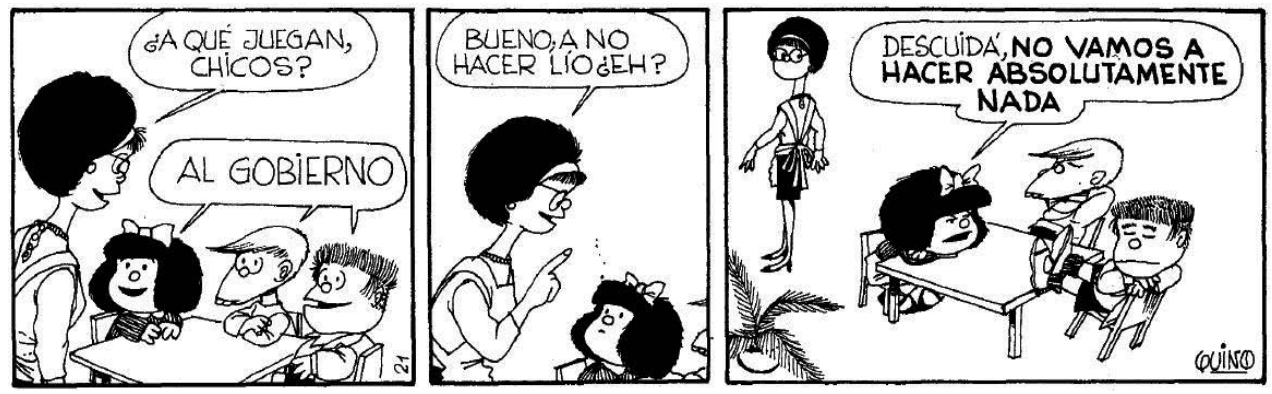

A partir de esta reflexión inicial, se plantean algunas cuestiones. ¿Es posible, en los casos narrados, exigir del Estado una reparación por su omisión? Si intuitivamente se tiene la gana de prontamente decir que sí, surge la pregunta: jurí-

\footnotetext{
1 Zero Hora (2011).

2 R7 (2011).
} 
dicamente, ¿qué criterios autorizan a decir que hay responsabilidad estatal? ¿Está la Administración obligada a reparar todo y cualquier caso de muerte natural? ¿Y si la persona se murió porque no había en los hospitales públicos un tratamiento para su enfermedad? ¿Y si el tratamiento cuesta 400 mil pesos? ¿Y si el tratamiento sólo existe en los Estados Unidos?

Este es el tema del presente ensayo: la responsabilidad del Estado en materia de derechos fundamentales económicos y sociales. ${ }^{3} \mathrm{Y}$ la forma elegida para enfrentarlo será a través del intento de contestar a dos preguntas: (i) ¿Qué se puede exigir directamente de la Administración Pública en materia de derechos sociales? (ii) ¿Cuáles son los requisitos necesarios para configurar la responsabilización del Estado por omisión?

\section{LOS DERECHOS FUNDAMENTALES ECONÓMICOS Y SOCIALES Y SU EXIGIBILIDAD ADMINISTRATIVA}

Sólo se puede hablar de responsabilidad por omisión en esta materia si antes se determina a qué está obligada la Administración para satisfacer derechos fundamentales económicos y sociales -como salud, educación, vivienda, asistencia social-, pues es precisamente el incumplimiento de un deber jurídico de actuar que la desencadenaría.

\section{La exigibilidad de los derechos fundamentales económicos y sociales más allá del minimo existencial}

A partir de la promulgación de la Constitución brasileña de 1988, la contradicción entre la vasta previsión normativa de derechos fundamentales y el pequeño grado de efectivación práctica de las disposiciones que los vehiculan llamó la atención de los juristas, sobre todo en el campo de la faceta prestacional de los derechos sociales, enunciados en el art. $6^{\circ}$ de la Ley Fundamental, tales como educación, salud, asistencia a los desamparados, seguridad social, entre otros. La cuestión se tornó aún más compleja frente a la disposición inscrita en el $\$ 1^{\circ}$ del

\footnotetext{
3 En este trabajo las expresiones "derechos sociales", "derechos económicos y sociales" y "derechos fundamentales sociales" serán utilizadas indistintamente, para designar los derechos fundamentales que tienen por objeto la tutela de bienes económicos, sociales y culturales imprescindibles para asegurar una vida digna, que el individuo también podría obtener de los particulares, si tuviera condiciones financieras para adquirirlos y los encontrara disponibles en el mercado. Sobre la caracterización de dichos derechos desde el contenido mencionado, consultar: Alexy (2007), p. 443; NovaIs (2010), p. 41.
} 
art. 5º de la Constitución Federal de Brasil, según la cual "las normas definidoras de derechos y garantías fundamentales tienen aplicación inmediata".

La literalidad de dicho dispositivo, sumada a la aspiración de extraer plena eficacia de las determinaciones constitucionales en materia de derechos fundamentales económicos y sociales, condujo a parte de la doctrina a sostener la posibilidad de postular judicialmente, ante las omisiones de la Administración Pública, la realización de estos derechos. Tales ideas lograron acogida por los tribunales, que, abandonando una postura conservadora, reticente a aceptar que con fulcro en las disposiciones definidoras de derechos sociales sería posible reclamar actuaciones estatales positivas, ${ }^{4}$ pasaron a certificar la fundamentalidad de los derechos sociales (en especial los derechos a la educación y a la salud) y encararlos como derechos subjetivos, prontamente exigibles frente al Poder Judicial.

No se puede negar, sin embargo, que en alguna medida ese avance implicó la adopción de un camino que pasó "de la falta de efectividad a la judicialización excesiva" 5 , especialmente en el área da la salud, resultando en la proliferación de "decisiones extravagantes o emocionales, que condenan a la Administración Pública al costeo de tratamientos irrazonables -ya sea porque inaccesibles, sea

4 En ese sentido, la siguiente decisión del Superior Tribunal de Justicia de Brasil, que reputa las disposiciones constitucionales referentes al derecho a la salud como "normas constitucionales meramente programáticas": "Normas constitucionais meramente programáticas - ad exemplum, o direito à saúde- protegem um interesse geral, todavia, não conferem, aos beneficiários desse interesse, o poder de exigir sua satisfação -pela via do mandamus- eis que não delimitado o seu objeto, nem fixada a sua extensão, antes que o legislador exerça o munus de completá-las através da legislação integrativa. Essas normas (arts. 195, 196, 204 e 227 da CF) são de eficácia limitada, ou, em outras palavras, não tem força suficiente para desenvolver-se integralmente, 'ou não dispõem de eficácia plena', posto que dependem, para ter incidência sobre os interesses tutelados, de legislação complementar. $\mathrm{Na}$ regra jurídico-constitucional que dispõe 'todos tem direito e o estado o dever' - dever de saúde- como afiançam os constitucionalistas, 'na realidade todos não têm direito, porque a relação jurídica entre o cidadão e o Estado devedor não se fundamenta em vinculum juris gerador de obrigações, pelo que falta ao cidadão o direito subjetivo público, oponível ao Estado, de exigir em juízo, as prestações prometidas a que o Estado se obriga por proposição ineficaz dos constituintes'”. BrasiL. Superior Tribunal de Justiça, Recurso Ordinário no Mandado de Segurança No 6.564/RS julgado em 23.05.1996. En el mismo influjo, la decisión del Tribunal de Justicia del Estado de Rio de Janeiro: "Mandado de segurança. Impetrantes portadores de insuficiencia renal crônica. Fornecimento de remédio (CELLCEPT) pelo Estado. As normas programáticas estabelecidas na Constituição Federal não conferem ao cidadão o direito subjetivo de exigir do Estado o fornecimento de remédios de alto-custo, em detrimento de outros doentes, igualmente carentes. $\mathrm{Na}$ consecução de sua obrigação de saúde pública a administração há que atender aos interesses mais imediatos da população. Impropriedade da via mandamental para atendimento do direito reclamado" Brasil. Tribunal de Justiça do Estado do Rio de Janeiro, Mandado de Segurança No 220/98, julgado em 17. 12.1998.

5 Barroso (2008), pp. 875-903. 
porque destituidos de esencialidad". $6 \mathrm{Y}$ con esto los tribunales pasaron a conceder prestaciones estatales gratuitas sin criterios. En materia de salud, hay, por ejemplo, un fallo en que la Suprema Corte Federal de Brasil condenó el Estado a costear el tratamiento de una enfermedad rara -la distrofia muscular de Duchene-, que solamente existía en los Estados Unidos y costaba a la época 63 mil dólares. ${ }^{7}$ ¿El fundamento? La Constitución brasileña prevé en el art. 196 que la salud es deber del Estado y derecho del ciudadano.

En las palabras de Luís Roberto Barroso, estos "excesos e inconsistencias (...) ponen en riesgo la propia continuidad de las políticas de salud pública, desorganizando la actividad administrativa e impidiendo la asignatura racional de los escasos recursos públicos". ${ }^{8}$ Además, la búsqueda de la efectivación de los derechos fundamentales económicos y sociales únicamente por la vía del Poder Judicial puede importar una "concesión de privilegios a algunos demandantes en detrimento de la generalidad de la ciudadanía, que continúa dependiente de las políticas universalistas implementadas por el Poder Ejecutivo"?

Frente a ese nuevo orden de problemas, y considerando que: (i) el acceso al Poder Judicial en Brasil es todavía limitado a la clase media y a la clase alta de la población; ${ }^{10}$ (ii) la mayor parte de las demandas son de carácter individual y no colectivo, lo que pone a los ciudadanos de bajos recursos -justamente los que más necesitan de la tutela estatal- en una situación desfavorecida en cuanto a la satisfacción de sus derechos; ${ }^{11}$ (iii) la planificación de políticas públicas universales,

6 Barroso (2008), p. 876.

7 "Entre proteger a inviolabilidade do direito à vida, que se qualifica como direito subjetivo inalienável assegurado pela própria Constituição da República (art. $5^{\circ}$, caput) ou fazer prevalecer, contra esta prerrogativa fundamental, um interesse financeiro e secundário do Estado, entendo - uma vez configurado este dilemaque as razões de índole ética-jurídica impõem ao julgador uma só e possível opção: o respeito indeclinável à vida”. BRASIL. Supremo Tribunal Federal. Medida Cautelar na Petição No 1246, julgado em 31.01.1997.

8 BARroso (2008), p. 876.

9 Barroso (2008), p. 876.

10 Refiriéndose a aquellos que no tienen acceso al Poder Judicial, Paulo Cezar Pinheiro Carneiro observa: “Trata-se de pessoas que não têm condições sequer de ser partes - os 'não-partes' são pessoas absolutamente marginalizadas da sociedade, porque não sabem nem mesmo os direitos de que dispõem ou de como exercêlos; constituem o grande contingente de nosso país". CARNeIro (1999), p. 58. Según Cláudio Pereira de Souza Neto, en investigación realizada en el Estado de São Paulo en el período de 1997 a 2004, que analizó todos los juicios propuestos, en $67,7 \%$ de los casos la parte autora estaba representada por abogados particulares. SouZA NeTO (2008a), pp. 533-534.

11 "No Brasil, assiste-se à predação da renda pública pela classe média e pelos ricos, especialmente nos casos de remédios estrangeiros, com o risco de se criar um impasse institucional entre o Judiciário e os poderes políticos, se prevalecer a retórica dos direitos individuais pelos sociais". TORRES (2009), p. 134. 
de carácter colectivo, destinadas a la concretización de oficio de los derechos de todos los ciudadanos, independientemente de provocación, compete a la Administración Pública; parte de la doctrina pasó a sostener la restricción del espectro de legitimidad del Poder Judicial en esta esfera a los casos en que el derecho fundamental social postulado es necesario para la garantía de condiciones mínimas de existencia digna al demandante -el llamado mínimo existencial-. ${ }^{12}$ Aparte de ese ámbito, la concretización maximizada de los derechos fundamentales económicos y sociales de carácter prestacional competiría a los Poderes Legislativo y Ejecutivo, de manera progresiva, mediante la prestación de servicios públicos y la implementación de políticas públicas. Es el posicionamiento acogido por diversas decisiones judiciales. ${ }^{13}$

Por lo tanto, la solución a que llegaron la doctrina y la jurisprudencia brasileñas, inspiradas en una decisión del Tribunal Constitucional Federal alemán, ${ }^{14}$ fue la siguiente: hay un contenido mínimo de los derechos sociales bajo el cual hay un consenso de que la dignidad de la persona fuera violada. Aquél comprende un conjunto de prestaciones mínimas de salud, alimentación, educación, vivienda, vestuario, al cual todos los ciudadanos tienen derecho, independientemente de previsión legal o constitucional, pues son condiciones sin las cuales no se puede siquiera ejercer los derechos de libertad. ${ }^{15}$

Este llamado mínimo existencial es prontamente exigible de la Administración Pública y, si ella no lo atiende, del Poder Judicial. La satisfacción de las parcelas de los derechos económicos y sociales que integran este mínimo no ofende la democracia, porque sin condiciones mínimas de existencia digna el ciudadano no puede participar democráticamente de los procesos de deliberación pública.

12 En ese sentido, entre otros: Torres (2004); Barcellos (2011).

13 A título de ejemplo: BrasiL. Superior Tribunal de Justiça. Recurso Especial No 811.608/RS, julgado em 15.05.2007; BrasiL. Supremo Tribunal Federal, Suspensão de Tutela Antecipada no Agravo Regimental No 175, julgado em 17.03.2010.

14 La decisión es del año 1975. Obsérvese parte del fallo: “(...) ciertamente la asistencia a los necesitados integra las obligaciones esenciales de un Estado Social. [...] Eso incluye, necesariamente, la asistencia social a los ciudadanos que, en virtud de su precaria condición física y mental, se encuentran limitados en sus actividades sociales, no presentando condiciones de proveer a su propia subsistencia. La comunidad estatal debe asegurarles al menos las condiciones mínimas para una existencia digna y emprender los esfuerzos necesarios para integrar estas personas a la comunidad, fomentando su acompañamiento y apoyo en la familia o por terceros, y creando las indispensables instituciones asistenciales". La traducción fue extraída de SARLET (2010), p. 318.

15 Barcellos (2011), p. 247. 
Y las parcelas que extrapolen este mínimo tendrán su exigibilidad dependiente de las elecciones del legislador.

Ocurre que, con fundamento en esa construcción teórica -según la cual la exigibilidad judicial de la dimensión prestacional de los derechos sociales se limita al contenido del mínimo existencial-, algunos autores pasaron a defender que la ius fundamentalidad de los derechos sociales estaría restringida a ese mínimo. ${ }^{16}$ En otras palabras: los derechos económicos y sociales serían fundamentales apenas y solamente cuanto a las porciones de estos derechos necesarias a asegurar condiciones mínimas de existencia digna al individuo. Más allá de ese mínimo, los derechos sociales no disfrutarían de la condición de derechos fundamentales, no incidiendo sobre ellos su régimen jurídico especial, dotado, entre otros factores, de aplicabilidad inmediata.

Se crea entonces la idea de que los derechos sociales son exigibles solamente en lo que sea necesario para garantizar el mínimo existencial. El problema de este raciocinio es que hay casos en que la propia Constitución garantizó prestaciones que exceden un mínimo para la existencia digna. Y hay, además, casos en que la propia ley aseguró contornos más amplios a los derechos fundamentales sociales que solamente el mínimo. Por ejemplo: la Constitución brasileña garantiza el derecho a la salud, pero no hace cualquier referencia a la gratuidad de estos servicios. Pero la Ley No 8.080/90 estableció la gratuidad de los servicios públicos de salud en su art. 43. Si un hospital público se niega a prestar gratuitamente un servicio de salud que, no obstante necesario, no integre el mínimo existencial, y el ciudadano sufre un daño a su integridad física o psicológica, ¿no puede él exigir una reparación?

La problemática central que emerge sobre el tema del reconocimiento de los derechos sociales como derechos fundamentales reside en la dificultad de aceptarse la aplicabilidad inmediata de las normas constitucionales que los consagran (en los términos del art. $5^{\circ}, \$ 1^{\circ}$, de la $C F$ ), ya sea ante la Administración Pública, sea ante el Poder Judicial. Eso, porque esta -la aplicabilidad inmediata- es una de las principales peculiaridades que caracteriza el régimen jurídico especial que el constituyente de 1988 otorgó a los derechos fundamentales.

Bajo la perspectiva jurídico-dogmática, hay un aspecto peculiar de la teoría de los derechos fundamentales contemporánea que permite responder, en cualquier ordenamiento constitucional, a las críticas largamente evocadas para apartar la incidencia directa de los derechos económicos y sociales y, como consecuencia,

16 Torres (2003), pp. 349-374; Maurício Jr. (2009), p. 47. 
retirarles la característica de fundamentalidad. Se trata de la multifuncionalidad de los derechos fundamentales.

\section{La multifuncionalidad de los derechos fundamentales y la unicidad de tratamiento jurídico de los llamados "derechos de libertad" $y$ de los "derechos económicos y sociales"}

El tema es explicado con claridad por Robert Alexy. Según el autor, los derechos fundamentales deben ser encarados como haces de posiciones ius fundamentales, es decir, cumple observar cada derecho fundamental como un "derecho fundamental como un todo"17. Significa decir que los derechos fundamentales son multifuncionales, ${ }^{18}$ de manera que no es posible asociarlos a una función única: de cada derecho fundamental pueden ser extraídos múltiples deberes, decurrentes de incumbencias de distinta naturaleza, que ellos encomiendan al Estado. Por lógica consecuencia, un determinado derecho fundamental investirá su titular en diversas posiciones jurídicas de caracteres diferenciados, y con base en cada una de ellas el ciudadano podrá reclamar diferentes obligaciones del Poder Público.

Las varias funciones adscritas a los derechos fundamentales son separadas por el autor en dos grandes bloques: (1) función de defensa; (2) función de prestación. Dentro del segundo, Alexy propone la siguiente división: (2.1) función de prestaciones fácticas (sentido estricto); (2.2) función de prestaciones normativas (sentido amplio). Este último subgrupo se separa en (2.2.1) función de protección; (2.2.2) función de participación en la organización y en el procedimiento. Esclarézcase lo siguiente: esa comprensión no sugiere que determinados derechos fundamentales se encuadran en la primera función, mientras los otros se encajan en las demás, sino que cada derecho fundamental posee, concomitantemente, esas diversas dimensiones, pudiéndose extraer deberes estatales correlatos a cada una de ellas.

La función de defensa de los derechos fundamentales se liga a la perspectiva que la doctrina normalmente asocia a los llamados derechos de libertad, o de primera generación o dimensión. Se relaciona a la prohibición de interferencia indebida en la esfera particular de su titular, ya sea derivada de acciones del Poder Público, ya sea de sujetos privados. Impone una conducta omisiva, de abstención del Estado. La dimensión defensiva del derecho a la libertad de expresión, por

\footnotetext{
17 Alexy (2007), p. 214.

18 Tal aspecto es resaltado por Ingo Sarlet, al mencionar que "varias de las normas definidoras de derechos fundamentales ejercen simultáneamente dos o más funciones, siendo, en este sentido, inevitable alguna superposición”. Cfr. SARLET (2010), p. 166.
} 
ejemplo, hace recaer sobre el Estado la interdicción de afectar las manifestaciones de pensamiento de su titular, cuando no haya expresa autorización para ello, prevista en una ley afinada al texto constitucional. Como ella se vincula a una de las primeras funciones reconocidas a los derechos fundamentales, son innúmeros los mecanismos colocados a la disposición de sus titulares por el ordenamiento jurídico para promover la defensa de estos derechos, pudiéndose citar, ilustrativamente, el "habeas corpus"19 y el "mandado de segurança"20, ambos asegurados en forma de garantías fundamentales por el art. $5^{\circ}$ de la Constitución brasileña.

La faceta prestacional de los derechos fundamentales se revela en las posiciones jurídicas que imponen al Estado la persecución de determinados objetivos, ${ }^{21}$ exigiéndose la creación de las condiciones fácticas y jurídicas necesarias para el ejercicio de los derechos. El aspecto prestacional puede presentarse de variadas formas, conforme a la naturaleza de la prestación exigida por la norma de derecho fundamental. Podrán ser prestaciones en sentido estricto (también llamadas de materiales o fácticas), englobando las pretensiones jurídicas del individuo frente al Estado a algo que, si él poseyese medios financieros suficientes y si encontrara en el mercado una oferta satisfactoria, podría obtener también de los particulares, ${ }^{22}$ tales como los servicios de educación y salud. El atendimiento de esa función es lo más complicado, sobre todo en función de la dificultad relativa a la escasez de recursos.

Las acciones positivas exigidas por la función de prestación podrán, por otra parte, constituir prestaciones en el sentido amplio, también comprendidas como prestaciones normativas. Son los derechos a la elaboración de normas por el Poder Público, ya sea por el Legislativo o por el Ejecutivo, ${ }^{23}$ necesarias para la protección de determinados bienes jurídicos (función de protección) o para la creación de organizaciones y procedimientos que auxilien en la promoción y en la protección

19 Constitución de la República Federativa de Brasil: “Art. 5. (...) LXVIII - se concederá 'habeas corpus' siempre que alguien sufra o se hallare amenazado de sufrir violencia o coacción en su libertad de locomoción, por ilegalidad o abuso de poder".

20 Constitución de la República Federativa de Brasil: "Art. 5. (...) LXIX - se concederá mandado de segurança para proteger derecho líquido y cierto, no amparado por 'habeas-corpus' o 'habeas-data', cuando el responsable por la ilegalidad o abuso de poder fuere autoridad pública o agente de persona jurídica en el ejercicio de atribuciones del Poder Público".

21 Alexy (2007), p. 393.

22 AleXY (2007), p. 443.

23 Sobre la actividad legislativa del Poder Ejecutivo, ver, por todos: CLÈvE (2011a). 
de los derechos fundamentales (función de participación en la organización y en el procedimiento).

La función de protección deriva de la propia dimensión objetiva de los derechos fundamentales, que atribuye a los Poderes Públicos el deber de protegerlos contra acciones de terceros. ${ }^{24}$ Son diversos los bienes que pueden exigir protección ius fundamental, tales como la salud, la vida, la dignidad y la libertad, y son variadas las formas mediante las cuales el Estado proveerá esa protección (v.g., normas de Derecho Penal, de Derecho Civil, de Derecho Procesal y de Derecho Administrativo). ${ }^{25}$ Cuanto a la función de participación en la organización y en el procedimiento, ella otorga al Estado el deber de emitir normas jurídicas -legislativas y/o administrativas- con el propósito de crear estructuras organizacionales y procedimentales que posibiliten el ejercicio de los derechos fundamentales. Se parte de la premisa de que "la fruición de diversos derechos fundamentales no se revela posible o, al menos, pierde en efectividad, sin que sean colocados a la disposición prestaciones estatales en la esfera organizacional y procedimental" 26 . Es el caso del derecho fundamental al sufragio universal y al voto directo y secreto: no se puede ejercitar el derecho de votar previsto por el art. 14 de la Constitución brasileña si el Estado no propicia la previsión normativa de la organización y del procedimiento electoral. Un individuo desproveído de recursos y acusado en una acción criminal tampoco tendrá medios eficientes de gozar del derecho a la asistencia jurídica gratuita (art. $5^{\circ}$, LXXIV, de la Constitución brasileña) sin la creación, por medio de normas jurídicas, de la estructura organizacional de la Defensoría Pública ${ }^{27}$ y de instrumentos procesales adecuados a la tutela de su libertad.

\footnotetext{
24 Alexy (2007), p. 398.

25 Importa señalar la distinción entre la función de defensa y la función de protección de los derechos fundamentales. Mientras la primera impone al Estado el deber de omitir intervenciones, la segunda le otorga el encargo de impedir, por medio de prestaciones positivas, que terceros practiquen intervenciones indebidas. Cfr. AleXY (2007), p. 404.

26 Sarlet (2010), p. 196.

27 Constitución de la República Federativa de Brasil: "Art. 134. La Defensoría Pública es institución esencial a la función jurisdiccional del Estado, incumbiéndole la orientación jurídica y la defesa, en todos los grados, de los necesitados, en la forma del art. 5 ${ }^{\circ}$, LXXIV. \$1 $\$$ Ley complementaria organizará la Defensoría Pública de la Unión y del Distrito Federal y de los Territorios y prescribirá normas generales para su organización en los Estados, en cargos de carrera, proveídos, en la clase inicial, mediante concurso público de pruebas y títulos, asegurada a sus integrantes la garantía de la inamovilidad y prohibido el ejercicio de la abogacía fuera de las atribuciones institucionales".
} 
Alexy bien ilustra la multifuncionalidad de los derechos fundamentales al ejemplificar con el derecho fundamental al medio ambiente ecológicamente equilibrado, que, así como los demás, está formado por un haz de posiciones jurídicas distintas. En este derecho están incluidos diversos desdoblamientos, tales como: (i) el derecho a que el Estado se abstenga de promover intervenciones atentatorias contra el medio ambiente (función de defensa); (ii) el derecho a que el Estado proteja a los ciudadanos de intervenciones de terceros que lesionen al ambiente (función de protección); (iii) el derecho a que el Estado permita al titular del derecho participar de procedimientos relevantes para el medio ambiente (función de participación en la organización y en el procedimiento); y (iv) el derecho a que el propio Estado emprenda providencias materiales, dirigidas a la mejora del medio ambiente (función de prestación fáctica). ${ }^{28}$

Los derechos fundamentales, por lo tanto, gozan de esa particularidad. No son derechos simples, a los cuales corresponde apenas un deber respectivo. Son haces de posiciones ius fundamentales, es decir, derechos que conceden a sus titulares un conjunto variado de posiciones jurídicas dotadas de tutela reforzada, y que imponen al Poder Público una gama diversificada de obligaciones correlativas a las diferentes funciones ejercidas por cada una de esas posiciones.

Con apoyo en esa característica es que se pretende explicar la sujeción plena de los derechos económicos y sociales al régimen jurídico de los derechos fundamentales. Las objeciones manejadas para cuestionar la aplicación inmediata de los llamados derechos sociales y, por consecuencia, su ius fundamentalidad, derivan de un equívoco elemental. Ellas asocian los derechos de libertad solamente a la función de defensa, clasificándolos como "derechos de defensa", y relacionan los derechos sociales solamente a la función prestacional, rotulándolos de "derechos a prestaciones". Y es justamente en este punto donde reside el gran problema: en la mayor parte de las veces se tiene en cuenta solamente una de las funciones a ellos inherentes, considerándola como si fuera la única y se ignora la evidencia de que los derechos económicos y sociales, así como todos los demás derechos fundamentales (inclusive los de libertad), son multifuncionales. ${ }^{29}$ En otras palabras: se olvida de la perspectiva de los "derechos fundamentales como un todo", según la cual cada derecho fundamental representa un haz de posiciones ius fundamentales del cual emanan deberes de respeto (función defensiva), de protección (función protectiva) y de prestación (función prestacional).

28 Alexy (2007), p. 392.

29 NovaIs (2010), p. 34. 
El problema no está en los derechos económicos y sociales, en sí mismos considerados, sino en los obstáculos a la implementación de las funciones protectiva y prestacional de los derechos fundamentales en general. Cada una de las funciones ejercidas por un derecho fundamental $-\mathrm{O}$, en otros términos, cada una de las posiciones jurídicas que de él emanan- plantea problemas diferentes, a los cuales deben ser dadas soluciones diferentes. ${ }^{30}$ Es errónea, por ello, la imputación de los problemas de aplicación inmediata a los derechos sociales, pues en realidad ellos conciernen a las funciones de prestación (fácticas, de protección y de participación en la organización y en el procedimiento) que derivan de todo y cualquier derecho fundamental.

No se puede asociar automáticamente derecho de libertad con "derecho de defensa" y derecho social con "derecho a prestaciones". Es preciso comprenderlos como "derechos fundamentales como un todo", que invisten a su titular de varias posiciones jurídicas: de defensa (contra acciones del Estado), de protección (contra intervenciones de terceros, evitadas por el Estado) y de prestación (promoción de acciones materiales por el Estado). Es más adecuado analizar el régimen de cada una de esas funciones de los derechos fundamentales, en lugar de intentar establecer un régimen específico para el bloque de los "derechos de libertad" y otro para el grupo de los "derechos económicos y sociales". ${ }^{31}$

\section{La aplicabilidad inmediata de los derechos fundamentales económicos y sociales en la perspectiva jurídico-subjetiva frente a las distintas funciones de los derechos}

La tarea que se impone, en este momento, es averiguar, o al menos intentar esbozar, cuáles son los grados de aplicabilidad inmediata de las diferentes funciones de los derechos fundamentales económicos y sociales -ya sintetizadas en defensa (deber de respeto), protección (deber de protección) y prestación (deber de promoción) - ante la Administración Pública.

La mayor dificultad está en conferir aplicabilidad inmediata a las prestaciones positivas (deberes de protección y de promoción) necesarias a la satisfacción de derechos fundamentales, sean de libertad o sociales. No se puede negar que hay, efectivamente, diferencias de exigibilidad ante la Administración cuando se trata de un deber negativo o de un deber positivo. La razón es que, aunque no haya

30 NovaIs (2010), p. 35.

31 Bittencourt Neto (2010), pp. 151-152. 
reglamentación legislativa de los contornos de determinado derecho fundamental constitucionalmente previsto, cuando se cuida del deber de respetar (función de defensa) no hay grandes controversias en cuanto al contenido del derecho: basta que el Estado se omita, que no intervenga. Cuando están involucrados, por otra parte, los deberes de protección y de promoción, que demandan prestaciones positivas, se torna más difícil exigirlos administrativamente cuando los delineamientos de su contenido no están trazados previamente por la Constitución o por la legislación. ${ }^{32}$ ¿Cuál sería, en estos casos, el contenido de los deberes estatales positivos, frente a la ausencia de previa delimitación normativa? Percíbase que no se está acá afirmando que es más difícil requerirse ante la Administración Pública la satisfacción de un derecho social que de un derecho de libertad, sino las funciones protectiva y prestacional de cualquiera de estos derechos fundamentales, si comparadas con la función defensiva.

Emerge, en este escenario, la cuestión atinente a la separación de los poderes y al principio democrático. Es plenamente compatible con dichos postulados la exigibilidad de la dimensión negativa de los derechos fundamentales, una vez que no hay dudas de que intervenciones indebidas en el ámbito de estos derechos son prohibidas constitucionalmente. Ocurre, sin embargo, que en relación con la dimensión positiva es, en alguna medida, más cuestionable la aceptación de que el Poder Ejecutivo o el Poder Judicial puedan realizar elecciones políticas cuanto al contenido, extensión y alcance de estos derechos, los cuales, por regla general, deberían ser delimitados por el Poder Legislativo en el campo del debate público y democrático, legitimado por la población para la toma de decisiones políticas. No obstante, esta conclusión nos puede llevar a otra, en el sentido de que la mayor dificultad de exigibilidad de las prestaciones positivas implica, necesariamente, la imposibilidad de postulación administrativa de los derechos sociales y su encuadramiento en la categoría de derechos fundamentales, pues, como hemos visto, no hay una correspondencia definitiva entre los derechos sociales y las obligaciones estatales positivas. ${ }^{33}$

Es preciso reconocer que los derechos de libertad también gozan de exigibilidad más reducida cuando se está en juego su dimensión positiva. Tómese el ejemplo de los derechos a la vida y a la integridad física: nadie cuestionará la posibilidad de postularse administrativa o judicialmente una protección contra la eventual amenaza de afectación estatal a estos derechos (deber de respetar la

32 Novals (2010), p. 127.

33 Novais (2010), pp. 129-130. 
vida y la integridad física); pero cuando está en cuestión el deber de protección, en su dimensión positiva (evitar que terceros violen los derechos referidos), su sindicabilidad se torna cuestionable. ¿Hasta qué punto y en qué medida el Estado está obligado a evitar toda y cualquier agresión de terceros a la integridad física de los individuos? Si es cierto, por una parte, que el Poder Público debe disponer de fuerzas policiales para operar medidas preventivas y represivas contra embestidas nocivas a la vida y a la integridad física de los particulares, no se puede negar, de otra parte, que hay dudas en relación con el lugar, el momento y la intensidad precisas de esta actividad. 34

Frente a tales ilaciones, se verifica que en materia negativa, cuanto al deber de respeto del Estado (no interferencia), hay identidad en la exigibilidad de los derechos de libertad y de los derechos sociales: ella será plena. ${ }^{35}$ La primera conclusión a que se puede llegar, entonces, en vez de (i) independientemente de la ausencia de reglamentación infraconstitucional, y por menor que sea la especificación constitucional de su contenido, la función de defensa de los derechos fundamentales económicos y sociales es inmediatamente aplicable en un grado máximo. Si los derechos sociales tienen por objeto la tutela de bienes económicos, sociales y culturales que el individuo podría obtener también de los particulares, ${ }^{36}$ en el caso de él poseer condiciones financieras para adquirirlos y los encuentre disponibles en el mercado, al incorporarse a su patrimonio, se encuentran blindados contra interferencia del Poder Público, el que en virtud de la ley reglamentaria estará impedido de afectarlos. Prohibiciones impuestas al Estado, tales como la adopción de prácticas y conductas nocivas a la salud de los ciudadanos o la interferencia en la forma de educación particular elegida por el individuo, pueden ser prontamente reivindicadas ante la propia Administración Pública o el Poder Judicial, en su integralidad.

Obsérvese el problema de restringirse la ius fundamentalidad de los derechos sociales al mínimo existencial: éste engloba apenas una parcela de aquéllos. La adopción de este mínimo como criterio para definir cuáles parcelas de los derechos sociales pueden ser protegidas por la vía administrativa o judicial puede llevar a una interpretación equivocada de que, también en el caso de deberes negativos (respeto), sólo se puede postular aquello que se limita al mínimo existencial. Con esto, se estaría negando la plenitud eficacial de la función defensiva de la integralidad de los derechos económicos y sociales.

\footnotetext{
34 Novals (2010), pp. 129-131.

35 Novais (2010), p. 135.

36 Alexy (2007), p. 443.
} 
El primer punto está resuelto: los deberes de respeto (prohibición de intervención estatal) a los derechos fundamentales económicos y sociales son totalmente susceptibles de postulación ante la Administración Pública. Se pasa entonces al análisis del grado de aplicabilidad inmediata de los deberes de protección (contra actuaciones de otros particulares) y promoción (prestaciones fácticas positivas) de estos derechos.

Independientemente de la inexistencia de cualquier ley disciplinadora, es incuestionable la necesidad de inserir en la esfera de aplicabilidad inmediata aquel que se ha tornado el mínimo denominador común de la doctrina brasileña en materia de justiciabilidad de derechos fundamentales sociales: el mínimo existencial. Puntúese, entonces, la segunda conclusión: (ii) las prestaciones estatales positivas destinadas a la satisfacción de derechos fundamentales sociales que integren el minimo existencial serán siempre exigibles ante la Administración Pública de forma definitiva, e independientemente de reglamentación legislativa, previsión presupuestaria, disponibilidad financiera o existencia de estructura organizacional del Poder Público para atenderlas. Al mínimo existencial no pueden ser opuestos argumentos en contrario, sujetándolo a la ponderación, tal como se acepta cuando se cuidan de prestaciones que exceden a las condiciones mínimas de existencia digna. Ello enflaquecería el instituto y le retiraría la funcionalidad. La inexistencia de estructura adecuada y condiciones fácticas, por parte del Estado, para efectivarlo, impone su condenación al costeo de servicios privados equivalentes.

El mínimo existencial debe ser considerado un piso mínimo, demarcando las prestaciones que el Estado no puede negar en ocasión alguna. Más allá de este mínimo, es aceptable la demanda de parcelas de derechos fundamentales sociales que le extrapolen, siempre que se observe una importantísima exigencia: debe ser posible deducir directamente del texto constitucional los contornos de las prestaciones que se pretende postular. No se defiende, por consiguiente, que cualquier pretensión vinculada a un derecho fundamental social pueda ser satisfecha por el juez, como si a él le incumbiera ponderar caso a caso acerca de la razonabilidad del pedido. El criterio propuesto para las parcelas de derechos fundamentales sociales que no están incluidas en el mínimo existencial es: si ya hay normatización de la Constitución sobre el tema, aunque ultrapase los límites del mínimo, esta prestación del derecho fundamental social podrá ser requerida ante el juez por gozar de aplicabilidad inmediata, nota característica del régimen jurídico de los derechos fundamentales.

Como consecuencia, la tercera proposición acerca de la aplicabilidad inmediata de los derechos fundamentales sociales es que: (iii) tratándose de prestaciones 
estatales positivas en materia de derechos fundamentales económicos y sociales, aunque inexistente ley reglamentaria, podrá ser postulado administrativamente o judicialmente el contenido especificado por el texto constitucional, mismo que desborde del minimo existencial. Aunque carentes de reglamentación legislativa, los derechos fundamentales sociales disfrutan de un contenido preestablecido por el constituyente. Y como la posición acá adoptada reconoce la ius fundamentalidad de los derechos sociales más allá del mínimo existencial, se impone la aceptación de exigibilidad de estos derechos no limitada al conjunto de prestaciones que lo integran.

Esta comprensión del contenido ius fundamental de los derechos económicos y sociales - dotado de aplicación inmediata- más allá del mínimo existencial no es tarea difícil en Constituciones como la brasileña, generosa en disposiciones que reglamentan estos derechos. Ella adelanta "en la mayor parte de los casos, normas de organización, deberes y posiciones activas que derivan de las disposiciones ius fundamentales" ${ }^{37}$ En el contexto brasileño actual, la Constitución se encuentra llena de disposiciones normativas que disciplinan el contenido de los derechos fundamentales sociales. A pesar de enunciarlos abstractamente en el art. $6^{\circ}$-"Son derechos sociales la educación, la salud, la alimentación, el trabajo, la vivienda, el descanso, la seguridad, la jubilación, la protección de la maternidad y de la infancia, la asistencia a los desamparados, en la forma de esta Constitución”-, la Ley Fundamental de 1988 retoma la regulación jurídica de los derechos sociales en su Título VIII, "Del Orden Social”.

La salud es tratada por los arts. 196 a 200 y ganó mayor especificación con la Enmienda Constitucional No 29/2000, que incluyó párrafos e incisos en el art. 198, vinculando ingresos de la Unión, de los Estados y de los Municipios para acciones y servicios públicos de salud. La educación es reglamentada pormenorizadamente en los arts. 205 a 214, conteniendo inclusive la concesión de gratuidad del acceso a la educación básica, que envuelve la educación infantil, la enseñanza fundamental y la enseñanza media, reconociéndola como derecho público subjetivo del ciudadano. También hay la previsión de vinculación de ingresos públicos para actividades destinadas a la educación, inserida por la Enmienda Constitucional No 14/1996.

La especificación constitucional de contenidos ocurre, igualmente, con los derechos a la jubilación social -arts. 201 y 202 y sus diversos párrafos, que establecen, inclusive, los criterios para la garantía de jubilación en el régimen general de los trabajadores de la iniciativa privada- y a la asistencia social (arts. 203 y

37 Bittencourt Neto (2010), p. 146. 
204, reconociéndose expresamente en el inciso V del primero la garantía de un salario mínimo de beneficio mensual a la persona portadora de deficiencia y al anciano que comprueben no poseer medios de proveer a la propia manutención o de tenerla proveída por su familia).

Todas esas delimitaciones de los contornos de los derechos fundamentales sociales operadas directamente por la Constitución pueden ser reclamadas ante la Administración o en juicio, aunque no reglamentadas por ley y lo mismo si ultrapasaren las prestaciones necesarias para garantizar una existencia mínimamente digna. No es necesario, en estos casos, el "mandado de injunção", 38 porque se trata de decisiones políticas fundamentales emprendidas por el constituyente, que siquiera están en la esfera de disponibilidad del legislador ordinario. Por lo tanto, son también prontamente exigibles.

Cuanto a la exigibilidad judicial, la dimensión prestacional de los derechos fundamentales no disciplinados por la legislación sólo será plenamente justiciable por los medios procesales comunes si es posible extraer directamente de la Constitución los trazos que componen su contenido, permitiendo la identificación precisa de las prestaciones específicas que otorgan derechos subjetivos a prestaciones materiales. Un ejemplo es el derecho de los ancianos mayores de 65 años a la gratuidad del transporte colectivo urbano, situado fuera del catálogo de derechos fundamentales (art. 230, $\$ 2^{\circ}$, Constitución brasileña), pero a él reconducible por medio de la cláusula de apertura material del art. $5^{\circ}, \$ 2^{\circ}$, de la Constitución brasileña. Aunque no se considere acá que esa pretensión jurídica esté incluida en el mínimo existencial, ${ }^{39}$ se reputa posible reclamarla jurisdiccionalmente frente a su violación. No se trata de disposición que exige ley ordinaria para ser postulada.

Regístrese que esa tercera proposición -(iii) - se aplica tanto a los deberes de promoción (prestaciones materiales del Estado) cuanto a los deberes de protección (contra actos de otros particulares) de los derechos fundamentales sociales. Los derechos de los trabajadores enunciados en los arts. $7^{\circ}, 8^{\circ}$ y $9^{\circ}$ de la Constitución de Brasil pueden ser exigidos judicialmente, obligando el Poder Público a protegerlos contra la acción de los empleadores, en la medida en que estén bien especificados en el texto constitucional, aunque no haya ley reglamentaria. Mis-

38 Así lo entiende CLÈVE (2011b), p. 107.

39 El Supremo Tribunal Federal manifestó entendimiento diverso. A pesar de acá concordarse con el entendimiento de que esa prestación es exigible judicialmente, se discrepa de la conclusión de la Ministra Cármen Lúcia Antunes Rocha cuando entendió que dicha prestación estaba incluida en el mínimo existencial. Cfr. BrasiL. Supremo Tribunal Federal. Ação Direta de Inconstitucionalidade No 3768, julgado em 19.09.2007. 
mo que la disposición que vehicula el derecho lo condicione a la "forma de la ley", como es el caso de los incisos I, IV, X, XI, XII, XIX, XX, XXI, XXII, XXIII, XXVII del art. $7^{\circ}$, la previsión de un contenido mínimo del derecho posibilita su reivindicación judicial. Aunque no existiera fijación legal del valor del salario mínimo (art. 7o, IV, Constitución brasileña), por ejemplo, el dispositivo ya establece pormenorizadamente aquello que debe ser abarcado por este valor (atendimiento de las necesidades vitales básicas del trabajador y las de su familia con vivienda, alimentación, educación, salud, descanso, vestuario, higiene, transporte y jubilación social), permitiendo con ello su definición por el juez. ${ }^{40}$ En las hipótesis en que no hay este contenido constitucional mínimo, siendo imprescindible la determinación infraconstitucional del contenido de la prestación a ser exigida de otros particulares (v.g., participación del trabajador en los lucros o resultados de la empresa, conforme definido en ley - art. 7o, XI, Constitución brasileña), será necesaria la impetración de "mandado de injunção" (art. 5, LXXI, Constitución brasileña). ${ }^{41}$

Cuanto a los deberes de promoción (prestaciones fácticas), en los casos que dependan de conformación legislativa del contenido de la prestación, el Poder Judicial no podrá tomar las decisiones políticas y realizar las elecciones de prioridades en el manejo de los recursos públicos, pues éstas quedarán reservadas al espacio de deliberación pública propio del Poder Legislativo. ${ }^{42}$ Pero si ya existieren disposiciones infraconstitucionales disciplinando materia análoga, está autorizada, por

40 Es la posición de Mello (2010b), pp. 49-52. El autor va más allá, sosteniendo además la posibilidad de revisión judicial del valor, si está fijado en ley y no atienda a todas las necesidades establecidas en el art. $7^{\circ}$, IV, de la Constitución brasileña.

41 De acuerdo con dicho dispositivo: "se concederá 'mandado de injunção' siempre que la falta de norma reglamentaria torne inviable el ejercicio de los derechos y libertades constitucionales y de las prerrogativas inherentes a la nacionalidad, a la soberanía y a la ciudadanía". En otro trabajo, se sostuvo que ante la impetración de ese remedio constitucional, compete al Poder Judicial viabilizar el ejercicio del derecho, pudiendo prestar a la decisión efectos inter partes o erga omnes, conforme a las exigencias concretas de las situaciones de derecho material en juego. La regla general es la atribución de efectos inter partes; sin embargo, siendo difusos o colectivos los derechos en cuestión, se puede conferir efectos erga omnes a la decisión. En esta última hipótesis, "la mejor solución parece ser la siguiente: (a) el juez deberá, liminarmente, crear la solución adecuada a la satisfacción del derecho del titular en el caso concreto; (b) siendo la solución creada satisfactoria a la tutela del derecho, podrá la liminar concedida asumir carácter definitivo; (c) habiendo necesidad de elaboración de norma con alcance más amplio que la solución proveída liminarmente, cabrá al juez la utilización de todos los medios posibles para ampliar el debate acerca de la creación de la norma, promoviendo un diálogo constitucional entre todos los interesados, envolviendo los poderes estatales y la sociedad". HACHEM (2012), pp. 180-181.

42 Bittencourt Neto (2010), p. 150. 
la vía específica del "mandado de injunção", la viabilización judicial del ejercicio del derecho fundamental. Ilústrese con el derecho de los servidores públicos a una jubilación especial, con requisitos diferenciados para su concesión, en los casos de actividades de riesgo, perjudiciales a la salud y a la integridad física, o de discapacitados (art. 40, $\$ 4^{\circ}$, I, II, III de la Constitución brasileña). ${ }^{43}$ Se deduce de allí la cuarta conclusión: (iv) si no existe legislación que discipline al derecho, y si no hay en la Constitución parámetros minimos para la especificación del contenido del derecho fundamental, la existencia de disciplina infraconstitucional reglamentando materia análoga autoriza la reclamación en juicio por medio del "mandado de injunção".

¿Y cómo queda la cuestión relativa al contenido de los derechos fundamentales económicos y sociales que no se encuentra todavía delimitado por la Constitución ni puede ser delineado desde una reglamentación infraconstitucional de asuntos análogos? Esta indeterminación tendrá que ser suplantada por el legislador ordinario. Cuando, por cuestiones de igualdad y de seguridad jurídica, el legislador establece los contornos de un determinado derecho fundamental social, especificando su contenido capaz de ser exigido del Poder Público, la problemática de la indeterminación es, al menos, parcialmente resuelta.

A partir del momento en que hay una disciplina normativa en el nivel infraconstitucional determinando el contenido de los derechos fundamentales sociales, ellos se tornan, inclusive, más densos jurídicamente que los propios derechos fundamentales de libertad. Como estos últimos están sujetos a una reserva general inmanente de ponderación, debiendo ceder puntualmente, en el caso concreto, cuando colisionaren con otros bienes jurídicos fundamentales, al legislador es vedado (o, al menos, no recomendable) fijar criterios legales $a$ priori de resolución de esas situaciones de colisión entre derechos fundamentales. Se deja abierto a la Administración y al juez, para que en la situación concreta se interprete, en conformidad con el principio de la proporcionalidad, cuál derecho deberá prevalecer. Frente a esa expresiva dependencia de las circunstancias del caso concreto, el legislador acaba por trazar apenas un cuadro abierto, susceptible a la posterior apreciación de la Administración y del Poder Judicial. En el caso de los derechos fundamentales económicos y sociales, en cambio, desde el momento en que el legislador, mediante el debate democrá-

43 Constitución de la República Federativa de Brasil: “Art. 40. (...) $\$ 4^{\mathbf{o}}$ Es vedada la adopción de requisitos y criterios diferenciados para la concesión de jubilación a los subordinados al régimen de que trata este artículo, exceptuados, en los términos definidos en leyes complementarias, los casos de servidores: I - discapacitados; II - que ejerzan actividades de riesgo; III - cuyas actividades sean ejercidas bajo condiciones especiales que perjudiquen a la salud o la integridad física". 
tico, tomó las decisiones políticas necesarias para fijar el contenido preciso de las prestaciones estatales correspondientes a la satisfacción de estos derechos, ellos ganan un grado de concreción y densidad mayor que aquel de los derechos fundamentales de libertad. ${ }^{44}$

Se identifica, en esta línea, la quinta conclusión: (v) las prestaciones de derechos fundamentales económicos y sociales reglamentadas por ley podrán ser plenamente exigidas ante la Administración Pública y el Poder Judicial, no pudiendo oponerles, por regla general, los argumentos de la reserva del posible y de la separación de poderes. Estando disciplinado el derecho fundamental social, no hay más que invocar la reserva legal presupuestaria o el principio de la separación de poderes. Ello, porque las prestaciones legalmente establecidas ya reflejan las ponderaciones efectuadas por los representantes populares de forma democrática en el espacio adecuado de deliberación pública; ya fueron seleccionadas las prioridades estatales frente a los recursos financieros recaudados. No cabe, pues, al administrador o al juez emitir nuevos juicios de ponderación, contrariando aquello que ya fue establecido democráticamente por el legislador, excepto, obviamente, que el contenido de la ley ofenda al propio texto constitucional, violando o no otros derechos fundamentales.

Podría alguien afirmar que esta última conclusión nada tiene que ver con la aplicabilidad inmediata de los derechos fundamentales, pues se basa en la propia legislación, tratándose, antes, de incidencia mediata. Pero de ella se extrae una consecuencia jurídica importante: los ciudadanos que no hubieren sido contemplados por la legislación, pero estén en situaciones fácticas semejantes, que exijan la misma normatización, podrán reivindicar con supedáneo en la aplicabilidad inmediata de los derechos fundamentales la extensión de los efectos de la reglamentación a su caso. El fundamento está en la prohibición de tratamiento discriminatorio. De acuerdo con Clèmerson Merlin Clève, la función de no discriminación de los derechos fundamentales ordena que el Estado provea a los individuos de manera igualitaria los bienes y servicios indispensables a su atendimiento (con excepción a las discriminaciones positivas, necesarias a proporcionar la igualdad material). De ello deriva la exigencia de que "los servicios sean colocados a la disposición de todos los brasileños (idea de universalidad), implicando para el particular el poder de reivindicar junto al Poder Judicial idéntico tratamiento". ${ }^{45}$

\footnotetext{
44 Novais (2010), p. 135.

45 ClÈVe (2011a), p. 102.
} 
Así, si hay dos titulares del mismo derecho fundamental social, en supuestos semejantes, y el legislador definió los contornos de este derecho beneficiando solamente a uno de ellos, el otro podrá exigir igual tratamiento con lastre en la incidencia directa de los derechos fundamentales. La aseveración deriva de la comprensión de que la disciplina normativa infraconstitucional integra el contenido del derecho fundamental, siendo también protegida por su régimen jurídico especial. La titularidad del derecho a aquellas prestaciones previstas en el nivel legislativo no es conferida a los ciudadanos por ley (según entendería la corriente que acepta la distinción entre derechos originarios y derechos derivados a prestaciones, estos últimos creados por la legislación): ella les es atribuida a ellos directamente por la Constitución. Así, aunque el ciudadano no esté contemplado por las disposiciones legales-situación en que, para él, habrá todavía falta de norma reglamentaria de su derecho-, él podrá exigir aquellas prestaciones estatales cuyo contenido fue legalmente especificado, con lastre en la aplicabilidad inmediata de los derechos fundamentales.

Una demostración puede ser verificada a partir del derecho a la revisión general anual del sueldo de los servidores públicos. Según el art. 37, X, de la Constitución brasileña, ellos poseen el derecho de tener su remuneración revisada anualmente, de acuerdo con la fijación del legislador. A pesar de no estar incluido en el Título II de la Constitución, se trata de derecho fundamental, por fuerza del art. $5^{\circ}, \$ 2^{\circ}$, una vez que deviene carácter alimentario y visa la protección de la sobrevivencia digna de los trabajadores públicos. Si en una determinada esfera federativa $-v . g$., municipal- hay la implementación legal de esta revisión, las categorías similares de servidores públicos que no hubieren recibido del legislador la fijación de su porcentual de revisión podrán, en virtud de la aplicabilidad inmediata del derecho fundamental a una remuneración digna, beneficiarse de esta concesión legislativa (que especifica el contenido de su derecho e integra su esencia) por imposición judicial.

No hay, en dicha situación, ninguna ofensa al principio democrático o de la separación de los poderes, pues los representantes populares, en el espacio de deliberación pública del Legislativo, ya establecieron prioridades en la asignación de los recursos públicos y definieron criterios para la aplicación de aquel determinado derecho fundamental. Y, por fuerza del principio constitucional de la igualdad, no se puede aceptar que ellos, deliberadamente, tengan decidido excluir los ciudadanos que se encuentran en circunstancias fácticas semejantes. Dicha opción no se encuentra dentro del margen conferido por la libertad de conformación del legislador, porque desborda de las limitaciones constitucionales a ella impuestas. 


\section{LA RESPONSABILIZACIÓN DEL ESTADO POR OMISIÓN}

\section{EN MATERIA DE DERECHOS SOCIALES}

Identificadas las prestaciones a las cuales la Administración Pública está obligada a satisfacer en materia de derechos fundamentales sociales, ante su exigibilidad directa frente al Estado, cumple enfrentar la segunda cuestión clave de esta investigación: ¿QQué elementos son exigidos para que surja el deber del Estado de reparar los daños causados por su omisión en materia de derechos fundamentales sociales?

El análisis de la cuestión reclama un estudio acerca de la teoría de la responsabilidad extracontractual del Estado, especialmente de la doctrina de la faute du service, pues en el Derecho Administrativo brasileño ha sido, en las últimas décadas, la más utilizada para fundamentar la responsabilización estatal en casos de omisión.

\section{Una propuesta de relectura de la teoría de la faute du service. El carácter objetivo de la responsabilidad por omisión y la innecesariedad de la perquisición de culpa}

Tamaña es la conexión entre la teoría de la faute du service y la idea de la ineficiencia del Estado pasible de provocar daños al ciudadano que es avalada por la mejor doctrina brasileña, considerándola como una modalidad de responsabilidad subjetiva, señala su aplicabilidad, aun en los días actuales, en los casos de omisión estatal. 46 Sustentan tales autores la posición de que "la responsabilidad por (...) faute du service (...) es responsabilidad subjetiva porque está basada en la culpa (o dolo)" y "cuando el daño fue posible debido a una omisión del Estado (el servicio no ha funcionado, ha funcionado tardíamente o ineficientemente) es de aplicar la teoría de la responsabilidad subjetiva”. ${ }^{47}$

Parece, sin embargo, haber otra interpretación posible, que se presenta más apropiada. Se pide venia para manifestar discordancia en relación con el entendimiento antes mencionado. Las consideraciones desarrolladas a continuación tienen por objetivo demostrar que la adopción de la responsabilidad subjetiva en el derecho brasileño, en los casos de responsabilidad del Estado por incumplimiento

\footnotetext{
46 Sostienen tradicionalmente esa posición, entre otros, algunos de los más ilustres administrativistas paulistas: Mello (1969), pp. 486-487; Mello (2010a), pp. 986-989 y 996-1001; Di Pietro (2010), pp. 654-656; Figueiredo (2008), p. 281.

47 Mello (2010a), pp. 987 y 996-997.
} 
del deber de eficiencia o en las situaciones omisivas (servicio que no ha funcionado o ha funcionado retrasado), no procede por lo menos por cuatro motivos: (a) la teoría de la faute du service no remonta a la responsabilidad subjetiva; (b) el criterio para distinguir la responsabilidad pour faute (por falta) de la responsabilidad sans faute (sin falta) en el Derecho francés no es la naturaleza omisiva de la conducta; (c) en Francia se admite hace mucho la hipótesis de responsabilidad objetiva del Estado por omisión; (d) los contornos de la responsabilidad estatal dependen del régimen jurídico-administrativo de cada ordenamiento, y la Constitución brasileña de 1988 impone un sistema de responsabilización objetiva.

(a) El primer argumento tendiente a apartarse de la interpretación anteriormente expuesta consiste en la imposibilidad de asociar directamente faute $d u$ service con responsabilidad subjetiva. Antes que todo, importa preguntar: ¡cuál es el significado de la palabra francesa faute?

La doctrina francesa, no raras veces apoyada en la formulación del civilista Marcel Planiol, explica el significado de la noción de faute como un incumplimiento de una obligación preexistente. ${ }^{48}$ Se incurre en falta (faute) cuando no se comporta como debería: "cuando la acción o abstención de actuar son conducentes a justificar una reprehensión". ${ }^{49}$ Los autores, al explicar la significación de la expresión, no hacen alusión a las tradicionales modalidades de culpa (negligencia, imprudencia e impericia), sino se refieren al hecho objetivo de inobservancia de un deber jurídicamente impuesto. Faute du service, por lo tanto, significa un comportamiento faltoso, violador de una obligación predeterminada por el Derecho positivo. Por esta razón, Jacqueline Morand-Deviller sostiene que la locución faute du service es deficiente y que sería preferible aludirse a "funcionamiento defectuoso del servicio" (fonctionnement défectueux du service) o a la "falta cometida en el ejercicio del servicio" (faute commise dans l'exercice du service). 50

La gran problemática en relación con la comprensión del sentido de la expresión faute du service se sitúa en la doble noción que la locución ostenta en el Derecho Administrativo francés. Laurent Richer, enfrentando de forma detenida la cuestión, explica que la principal noción de faute en el Derecho Administrativo francés es la objetiva, anteriormente señalada, que la comprende como el hecho material de incumplimiento de una obligación, desproveído de preocupaciones en

48 Chapus (1998), p. 1190; Morand-Deviller (1999), p. 750.

49 Chapus (1998), p. 1190.

50 Morand-Deviller (1999), p. 756. 
relación con aspectos subjetivos. En sus palabras: "La doctrina (...) considera que la faute du service sólo puede ser una noción 'objetiva'. Según los autores, ningún elemento subjetivo, ninguna referencia a la intención es concebible en materia de faute du service" . ${ }^{51}$ Por lo tanto, sería posible traducir la palabra al portugués y al español como "falta", no en el sentido de "ausencia", sino en la acepción de "infracción”, como se emplea comúnmente en el Derecho del Trabajo cuando se refiere a "falta grave" del trabajador.

Esa traducción de faute du service entendida como "falta cometida en el ejercicio del servicio" es la más adecuada, una vez que la comprensión de la expresión como "culpa" no resiste a un análisis más profundo. La referencia que hacen algunos autores franceses al término latino culpa (in eligendo e in vigilando) no permite decir que faute signifique culpa. Tómese como ejemplo Marcel Waline. Inicialmente, el autor afirma la incorrección de la expresión responsabilité pour faute, prefiriendo la terminología responsabilité conditionée par une faute, por entender que "una persona jurídica no es jamás responsable de su propia faute. Es uno de sus agentes o representantes que hayan cometido la faute, y es ella la que condiciona la responsabilidad de la persona jurídica". ${ }^{52}$ Además, el autor alude a las hipótesis de culpa in vigilando e in eligendo del Derecho civil, considerándolas como exigencias absurdas.

En la redacción de Waline queda claro que la acepción de la palabra faute no puede ser "culpa", so pena de admitirse la insensata hipótesis de que líneas antes el autor había afirmado que fue uno de los agentes públicos que "cometió la culpa". En el mismo sentido, otros autores como René Chapus y Michel Paillet utilizan la expresión "cometer una faute" 53 o "faute cometida". 54 Añádase a eso el hecho de que algunos autores hacen alusión a "agents (...) coupables d'une faute”55. ¿Cuál sería entonces la traducción de la locución?, ¿"agentes culpables por una culpa"? Por supuesto que no: lo sensato sería traducirla como "agentes culpables por una falta".

51 Traducción libre. En el original: "La doctrine (...) considère que de faute de service ne peut être q'une notion 'objective'. Selon les auteurs, aucun élément subjectif, acune référence à l'intention n'est concevable en matière de faute de service". RICHER (1978), pp. 6 y 88.

52 WaLINE (1959), p. 707.

53 Traducción libre. En el original: "commettre de faute". Chapus (1998), p. 1189.

54 Traducción libre. En el original: "faute commise". PaILlet (1980), p. 35.

55 Morand-DeViller (1999), p. 755. 
No se puede negar, sin embargo, que la jurisprudencia francesa utiliza, a veces, otra noción de faute, reputada como "marginal" por Laurent Richer. ${ }^{56}$ Se cuida de las hipótesis en que se tiene en cuenta la intención de causar daños y la voluntad de cometer un acto ilícito. En algunas situaciones $-\mathrm{y}$ no todas, destáquese- la jurisprudencia francesa requería la presencia de la noción culpable de faute para que la responsabilidad quedara configurada. La tendencia, no obstante, fue en el sentido de apartarse cada vez más de tal exigencia. Es solamente en este caso eventual, marginal, que según el autor "la faute du service est une 'culpa". ${ }^{57}$ En sus conclusiones, el jurista afirma que todavía somos asombrados por la vieja concepción punitiva de responsabilidad, como si la Administración pudiera ser culpable (coupable) y pudiera ser punida. Para él, tal noción utilizada por la jurisprudencia sólo podría ser defendida si toda faute du service suscitara una sanción disciplinar o una responsabilidad personal para el agente, que no es el caso. ${ }^{58}$

Así, no hace sentido intentar imputar culpa a la Administración, sino tan solamente perquirir el incumplimiento objetivo de un deber de actuar. Miguel $S$. Marienhoff, en profundizada monografía acerca del tema específico de la responsabilidad estatal por omisión, recuerda que la abstención sancionable, que da lugar a la responsabilidad, es aquella que deriva del incumplimiento de un determinado deber jurídico. Si la especie de responsabilidad bajo examen lleva en cuenta esencialmente el incumplimiento de la obligación por parte del Estado, se prescinde de la idea de culpa y se tiene, por consiguiente, una responsabilidad de naturaleza objetiva..$^{59}$ Es también esa la posición de Romeu Felipe Bacellar Filho, que incluye la falta de servicio en la modalidad objetiva de responsabilización, pues "ante el deber de eficiencia impuesto al Poder Público, se prescinde de cualquier perquisición de culpa, aunque especial" ${ }^{60}$

La Administración no tiene voluntad o conciencia, quien la tiene es el agente. Y si la faute du service depende de la individualización del agente, no se puede exigir la perquisición de "culpa" de la máquina estatal, sino el cometimiento de una conducta contraria a lo jurídicamente exigido.

Conforme explican Georges Vedel y Pierre Devolvé, la faute du service consiste en la falta imputable a uno o más agentes públicos, que no puede ser separada del

56 RICHER (1978), p. 88.

57 Richer (1978), p. 4.

58 RiCHER (1978), p. 171.

59 Marienhoff (2001), p. 67.

60 Bacellar Filho (2006a), p. 308. 
ejercicio de la función pública, es decir, no puede ser atribuida con exclusividad a la persona del agente. Los autores señalan, con marcado énfasis, que:

Contrariamente a lo que escriben algunas veces, la faute de service no se caracteriza por su carácter impersonal y anónimo. Como la Administración no tiene existencia física, sus faltas son siempre faltas de los individuos y es tan solamente por una operación jurídica que les imputa al servicio. En cuanto al carácter pretendidamente anónimo de la faute de service, él no es necesario. Hay faltas de servicios, cuyos autores son desconocidos, y otros cuyos autores son conocidos. La verdad es que, en los casos de falta de servicio, la víctima puede volverse en contra de la administración sin tener que nombrar nominativamente el agente que cometió la falta y cuya personalidad no importa cuando él no fuera accionado personalmente. ${ }^{61}$

En este exacto sentido, Marcel Waline aclara que en materia de responsabilidad estatal, no se puede tener en cuenta la personalidad de la entidad pública, ya que ella actúa siempre, necesariamente, por intermedio de un agente humano. La persona jurídica no posee, metafísicamente, voluntad propia. En realidad, es la voluntad de los agentes públicos que es imputada a la persona jurídica, de manera que siempre será uno o más agentes que practicaron la conducta que se imputa a la persona estatal. Cuando se dice que el Estado cometió una falta, fue, de hecho, uno de sus agentes quien la cometió. "En consecuencia”, concluye el administrativista francés, "no hay responsabilidad de la persona administrativa decurrente de hechos personales, tampoco de su falta, porque una persona jurídica no comete faltas; son las personas físicas que la representan que cometen las faltas". ${ }^{62}$ Es también este el entendimiento de René Chapus, según el cual "una persona jurídica (que es una abstracción) no podría ni querer, ni actuar, ni cometer una falta". 63

En efecto, tales consideraciones ya habían sido planteadas por Léon Duguit en 1913. De acuerdo con este jurista francés, en la doctrina tradicional del Derecho privado la noción de responsabilidad implica siempre la idea de faute, asumiendo la existencia de una persona con una voluntad consciente. Si hay la violación consciente de una regla, recae sobre el titular de la voluntad la responsabilidad.

61 Vedel y Devolvé (1992), p. 581.

62 Traducción libre. En el original: "Par conséquant, il n’y a pas de responsabilité de la personne administrative de son fait personnel, ni de sa faute; car une personne morale ne commet pas de faute; ce sont les personnes physiques qui la représentent, qui commetent les fautes”. WALINE (1959), p. 648.

63 Traducción libre. En el original: "une personne morale (qui est une abstraction) ne saurait ni vouloir, ni agir, ni commettre de faute”. CHAPUS (1998), p. 1189. 
Sin embargo, el administrativista señalaba, incluso en aquella época, que la "responsabilidad del Estado no está vinculada de forma alguna a la idea de culpa", de suerte que la referencia a la faute del Estado y de los servicios públicos sólo se explica por la influencia de las ideas civilistas. ${ }^{64}$

Adoptando tal raciocinio, se torna sin sentido hablar de "culpa de la Administración” o "culpa del servicio". Sólo pueden incurrir en culpa o dolo personas físicas, dotadas de subjetividad, ya que ambos son elementos subjetivos. Si en los casos de faute du service no se busca quién fue el agente responsable de la práctica de los daños, es incomprensible pretender evaluar si hubo culpa o dolo de la persona jurídica. Muy bien. Si de acuerdo con esa teoría el análisis de la conducta del agente es prescindible para configurar la responsabilidad del Estado hacia la víctima (si bien es necesario para permitir la posterior acción de regreso de la Administración frente al agente), también será innecesario el examen de la negligencia, imprudencia o impericia del representante del Estado responsable por el daño. Y excluyéndose del análisis la conducta del agente, se torna imposible evaluar la "culpa" de la Administración.

Por lo tanto, la faute du service puede ser entendida -y en este sentido, como se ve, la gran mayoría de la propia bibliografía francesa, nativa del lugar donde nació esta teoría-como todo incumplimiento de obligaciones del servicio. Ella puede consistir, como subrayan expresamente Georges Vedel y Pierre Devolvé, tanto en una acción como en una abstención. ${ }^{65}$ Teniendo en cuenta tales afirmaciones, extraídas de la propia bibliografía francesa, ¿cómo sería posible sostener que la teoría del faute du service se debe aplicar apenas en los casos de omisión y que ella requiere la comprobación de culpa de la Administración?

(b) Un segundo y sustancioso factor que demuestra la impropiedad de referirse a la teoría de la faute du service en los casos de omisión estatal en el Derecho brasileño -y, me atrevo a decir, en el Derecho argentino- está en el hecho de que este no es el criterio empleado en Francia para diferenciar las hipótesis de responsabilidad pour faute (por falta) y de responsabilidad sans faute (sin falta). La teoría de la faute du service no fue elaborada para aplicarse a las hipótesis de comportamiento omisivo. Ella tiene otro objeto: identificar las hipótesis en que la Administración debe ser compelida a indemnizar al ciudadano, sola (cuando no haya falta personal, que sea posible separar de la propia actividad administrativa)

64 Duguit (1913), p. 231. La palabra faute fue traducida por "culpa” por el autor estar refiriéndose a la noción civilista de faute, ésta sí conectada a la idea de culpa.

65 Vedel y Devolvé (1992), p. 581. 
o en solidaridad con el agente (en los casos de acumulación entre faute du service y faute personnelle).

La sistemática francesa de la responsabilidad civil del Estado, es menester subrayar, no se funda en la dicotomía responsabilidad subjetiva vs. responsabilidad objetiva. Una investigación atenta de las diversas obras que tratan específicamente del tema revela tal conclusión de manera inequívoca. La gran cuestión sobre la cual se funda tal sistemática reside en la necesidad o no de la ocurrencia de una falta (y no "culpa"), comprendida como el incumplimiento de una obligación jurídica. Las confusiones acerca de la teoría francesa de la responsabilidad estatal reposan sobre el equivocado intento de promoverse una lectura del ordenamiento francés con las lentes de otros sistemas jurídicos. Como la tradición local en el tema de la responsabilidad, en el caso del ordenamiento brasileño, se basa en el binomio responsabilidad subjetiva vs. responsabilidad objetiva, se torna muchas veces difícil desvincularse de este paradigma basado en la necesidad o no de culpa, para comprender adecuadamente la noción de faute del Derecho francés. No se puede, por lo tanto, asociar automáticamente responsabilité pour faute a la responsabilidad subjetiva, mucho menos restringirla a los casos de omisión, a pesar de la responsabilité sans faute ser siempre una responsabilidad objetiva.

La afirmación es de fácil comprobación. En los varios ejemplos de responsabilidad estatal por faute du service, los autores no hacen mención alguna a las ideas de negligencia, imprudencia e impericia. Mírese el caso citado por Richer, de inobservancia del principio de la adaptabilidad (o mutabilidad) del servicio público: si un hospital público debe proporcionar al enfermo cuidados en conformidad con los recursos tecnológicos actuales de la ciencia, al causarle un daño por tener sin adaptar sus equipos dentro de un plazo razonable estaría cometiendo una faute. Referencia alguna se hace a la necesidad de comprobación de negligencia o imprudencia del Estado. ${ }^{66}$

Si la teoría de la faute du service se aplica tanto para conductas comisivas cuanto a las omisivas, ${ }^{67}$ ¿por qué razón sería justificable su aplicación, en el Derecho brasileño, apenas en las omisivas? Si la teoría debe ser aplicada cuando el servicio funcionó mal, no funcionó o funcionó retrasado, ¿por qué en Brasil se debería emplearla apenas en los dos últimos casos (que configuran hipótesis de omisión)?68 Las tres situaciones revelan el incumplimiento al mismo deber de actuar: el prin-

66 Richer (1978), p. 37.

67 Esto lo afirman Waline (1959), p. 741; Vedel y Devolvé (1992), p. 581.

68 Es lo que sostiene la corriente de la responsabilidad subjetiva, como da noticia Di Pietro (2010), p. 654. 
cipio de eficiencia. Así que la consecuencia jurídica de ese incumplimiento debe ser la misma, sometiendo el Estado a un régimen uniforme de responsabilidad.

Por lo tanto, en el Derecho francés hay diversas situaciones que están sujetas al régimen de responsabilidad objetiva (sans faute), independientemente de tener derivado de acción u omisión. O sea, el criterio para distinguir responsabilidad subjetiva y objetiva en el Derecho francés no es, seguramente, el hecho del daño tener advenido de acción u omisión del Estado. Lo que se toma en cuenta para diferenciar el régimen de responsabilidad del Estado -subjetivo u objetivo- es la naturaleza de la actividad y no el exceso o inoperancia de la Administración.

(c) Otro argumento parece ser decisivo para suplantar completamente la exigencia de comprobación de culpa en los casos de omisión: tanto la doctrina cuanto la jurisprudencia francesas reconocen expresamente la existencia de hipótesis de responsabilidad objetiva del Estado por omisión. En el capítulo destinado a la responsabilité sans faute con fundamento en la teoría de la igualdad de los ciudadanos ante las cargas sociales, Georges Vedel y Pierre Devolvé ofrecen como ejemplo los casos de "abstención no faltosa" (abstención non fautive) de la Administración. ${ }^{69} \mathrm{El}$ argumento también se aplica a los que traducen faute por "culpa": en el Derecho francés se admite la responsabilidad del Estado por "abstención no culposa".

En la jurisprudencia del Consejo de Estado reclama referencia el caso Couitéas (Conseil d'Etat, 30 de noviembre de 1923). El señor Couitéas había comprado un terreno en Túnez sobre el cual estaban instaladas tribus indígenas, y para lograr el ingreso a la posesión consiguió una decisión judicial determinando la expulsión de las familias. En la oportunidad, la Administración utilizó su prerrogativa de negar auxilio policial a la ejecución de una decisión judicial en razón del riesgo de perturbar el orden público y el interés de la colectividad. Aunque la omisión tradujera el ejercicio de una prerrogativa amparada por el ordenamiento jurídico, desproveída de carácter faltoso o culposo, el Estado fue condenado a indemnizar al titular del título ejecutivo, por haber él soportado un sacrificio demasiado pesado en razón del interés público. ${ }^{70}$

Muy bien, si el propio Derecho francés, tanto en el ámbito doctrinario cuanto en el jurisprudencial, admite explícitamente la responsabilidad objetiva del Estado por omisión, ¿cuál sería la justificativa para negar tal posibilidad en el Derecho brasileño, utilizando paradójicamente una teoría francesa?

69 Vedel y Devolvé (1992), p. 491.

70 Long et al. (2007), p. 253. 
(d) Aunque se opte por aplicar la construcción teórica francesa, no se puede olvidar que el propio arrêt Blanco, al determinar que la responsabilidad del Estado debería regirse por sus propios principios, distintos de aquellos previstos en el Código Civil, afirmó de forma contundente que: (i) esa responsabilidad "no es ni general, tampoco absoluta" -por lo tanto, no puede olvidarse de las especificidades de cada Estado, cultura, historia y ordenamiento jurídico, aplicándose igualmente a todos los países y momentos históricos-,71 (ii) tal responsabilidad está sometida a "reglas especiales que varían conforme las necesidades del servicio y la necesidad de conciliar los derechos del Estado con los derechos privados" -luego, las reglas que orientan el sistema de responsabilidad se sujetan al régimen jurídico administrativo, debiendo conciliar las prerrogativas estatales y los derechos de los ciudadanos, tal como estatuidos por el Derecho positivo.

Por lo tanto, sólo se puede pretender la recepción, en Brasil o en Argentina, de las teorías de la responsabilidad civil desarrolladas en Francia cuando haya compatibilidad con sus respectivos regímenes jurídicos. Y, por lo menos en el caso brasileño, es justamente otra teoría -también aplicada en el Derecho francés-que se acomoda más adecuadamente al conjunto de principios y reglas que rigen la Administración Pública patria. Siendo así, importa aclarar algunos aspectos de la llamada responsabilidad sans faute en Francia, que pueden iluminar la construcción de una nueva comprensión de la responsabilidad objetiva del Estado en el Derecho brasileño, por acción u omisión, adaptada a su realidad normativa.

La reluctancia de parte de la doctrina en reconocer la responsabilidad por omisión como una hipótesis de responsabilidad objetiva se deriva del hecho de que, en el Derecho brasileño, es habitual hacer mención únicamente a la teoría del riesgo para explicar la responsabilidad objetiva, olvidándose de otra hipótesis largamente difundida en el Derecho francés más recientemente: la teoría (o principio) de la igualdad de los ciudadanos ante los encargos públicos. En general, los cursos y manuales contemporáneos subdividen la responsabilité sans faute en estos dos fundamentos: (i) teoría del riesgo, aplicable a las situaciones en que la Administración desarrolla, en nombre del interés general, actividades de riesgo excepcional, o (ii) teoría de la igualdad de los ciudadanos ante los encargos públicos, según la cual, si una actividad administrativa que es efectuada para beneficiar a todos ocasionara daños particulares sobre determinados individuos, el equilibrio normal se interrumpe y el principio de la igualdad resulta herido, de suerte que tal antijuridicidad debe ser reparada. ${ }^{72}$

71 La relatividad del régimen de responsabilidad del Estado es acentuada por Waline: WALINE (1959), p. 709.

72 Vedel y Devolvé (1992), p. 579. 
También distintamente de lo que se sostiene a veces en Brasil, el alcance de la teoría del riesgo es más restrictivo en el Derecho francés. Solamente las actividades que envuelven efectivamente un riesgo excepcional disfrutarán del régimen de responsabilidad objetiva con fulcro en la teoría del riesgo, tales como: daños causados a terceros por cuenta de trabajos públicos; bienes y métodos peligrosos y riesgo de vecindad; riesgo en la colaboración ocasional con el servicio público; riesgos profesionales. ${ }^{73} \mathrm{~A}$ su vez, la teoría de la igualdad de los ciudadanos ante los encargos públicos es igualmente limitada a determinadas hipótesis, tales como: responsabilidad decurrente de actos legislativos, de convenios internacionales, reglamentos y de decisiones administrativas regulares. ${ }^{74}$ Esta teoría, que en la mayor parte de las veces recibe referencias en el Derecho brasileño como el fundamento de la responsabilidad civil del Estado, consustancia en el Derecho francés una teoría autónoma de la responsabilidad objetiva del Poder Público, distinta de la teoría del riesgo.

El principio de igualdad de los ciudadanos ante los encargos sociales es reconocido incluso sin disposición expresa, por consistir en el despliegue del principio general de igualdad. Para Jacqueline Morand-Deviller, los principios fundamentales de la equidad y de la solidaridad inspiran el régimen de la responsabilidad objetiva: si es preciso aceptar que el buen funcionamiento de los servicios públicos y la utilización de las prerrogativas del Poder Público imponen a los ciudadanos ciertas cargas, aunque la Administración no practique ninguna falta, sería desigual que los ciudadanos lesionados no pudieran postular la reparación. ${ }^{75}$ En Brasil, Celso Antônio Bandeira de Mello, aunque no extraiga del principio las mismas consecuencias que aquí se pretende, lo reconoce como fundamento de la responsabilidad estatal, direccionado a garantizar una distribución equitativa de los encargos oriundos de actos o efectos dañinos, evitando que algunos soporten perjuicios causados por comportamientos practicados en el interés de todos. ${ }^{76}$

Esta parece ser la mejor teoría para fundamentar la opción del constituyente brasileño en la generalidad de los casos (si se adopta una concepción mucho más amplia que la presente en el Derecho francés): ${ }^{77}$ el principio de la igualdad en la

73 Morand-Deviller (1999), pp. 764-772.

74 Chapus (1998), pp. 1255-1270.

75 Morand-Deviller (1999), p. 765.

76 Mello (2010a), p. 991.

77 Para René Chapus, el principio de la igualdad ante los encargos sociales no constituye ni el fundamento de la responsabilidad civil del Estado en general, tampoco de la responsabilidad objetiva genéricamente 
distribución de los encargos sociales, en relación con la cual no queda ninguna duda en la doctrina francesa cuanto a su encuadramiento en las hipótesis de responsabilidad objetiva (sans faute). La opción por esta teoría, y no por la teoría del riesgo, se explica porque no toda actividad estatal presupone asunción efectiva de riesgos. No se puede poner al mismo nivel el desarrollo de actividades nucleares (artículo 21, XXII, "c" de la Constitución brasileña ${ }^{78}$ ) con la emisión de decretos reglamentarios, aunque ambas situaciones puedan dar lugar a responsabilización objetiva del Estado, si de tales actos derivaren daños específicos a los ciudadanos. Ambos son casos de responsabilidad objetiva por acción; sin embargo, en aquél efectivamente se aplica la teoría del riesgo; en éste, la teoría de la igualdad ante los encargos sociales.

En la omisión, el fundamento debe también ser el principio de igualdad. Si la Constitución brasileña de 1988 previó en sus principios fundamentales los objetivos de "construir una sociedad libre, justa y solidaria" (artículo $3^{\circ}$, I) y "reducir las desigualdades sociales" (artículo $3^{\circ}$, III), significa que prevalecen en la raíz del ordenamiento jurídico patrio, de forma inequívoca, los principios de equidad y solidaridad. Por lo tanto, si la responsabilidad civil del Estado debe ser interpretada a la luz del régimen jurídico-administrativo ${ }^{79} \mathrm{y}$ "en la exacta medida entre los derechos del Estado y los derechos del administrado" (arrêt Blanco), tanto en los casos de acción como en los casos de omisión se impone la adopción del sistema de responsabilidad objetiva.

Si el ciudadano pierde un riñón debido a la ausencia de una vacante en un hospital público, ¿por qué razón él tendrá que probar la culpa del Estado? ¿Y si no hubiera la culpa? ¿Y si el intendente de la Municipalidad y el gobernador de la Provincia hubieren puesto en práctica todos los recursos destinados a la salud, cumpliendo rigurosamente las leyes presupuestarias? No hay culpa en ninguna de sus modalidades (negligencia, imprudencia o impericia), mientras que hay el incumplimiento al principio constitucional de la eficiencia administrativa (el servicio público de salud no funcionó). En este caso, ¿no se verifica una situa-

considerada. Él basa solamente las hipótesis en que el ciudadano se ve obligado a soportar una carga particular en nombre del interés público (intérêt général). Chapus (1998), p. 1253.

78 Constitución de la República Federativa de Brasil: “Art. 21. Compete a la Unión: (...) XXII - explotar los servicios e instalaciones nucleares de cualquier naturaleza y ejercer el monopolio estatal sobre la investigación, la extracción, el enriquecimiento, el reprocesamiento, la industrialización y el comercio de minerales nucleares y sus derivados, cumpliendo los siguientes principios y condiciones: (...) c) la responsabilidad civil por daños nucleares no depende de la existencia de culpa”.

79 Bacellar Filho (2000), p. 15. 
ción de menoscabo al principio de la igualdad ante los encargos públicos? ¿Por qué razón este único ciudadano debe soportar por sí solo la carga de la falta de servicio público, sin que haya una socialización de la reparación de los perjuicios por él experimentados?

Por otra parte, el artículo $37, \$ 6^{\circ}$, de la Constitución brasileña, que traduce el fundamento normativo de la responsabilidad civil del Estado en Brasil, no hace distinción entre comportamientos omisivos y comisivos: "Las personas jurídicas de derecho público y las de derecho privado prestadoras de servicios públicos responderán por los daños que sus agentes, en esa calidad, causen a terceros, asegurado el derecho de regreso contra el responsable en los casos de dolo o culpa”. De este mandato se infiere un régimen uniforme de responsabilización, sea para excesos, sea para inoperancias de la Administración. Esta es la interpretación de Romeu Felipe Bacellar Filho, que en un estudio específico sobre el tema, afirma: "Si la Constitución Federal, en su superior posición, adopta la responsabilización objetiva, no hay cómo desconsiderar el mandamiento constitucional, incluso en la hipótesis de omisión". 80

El texto constitucional exige la comprobación de dolo o culpa tan sólo en el caso de la acción regresiva del Estado ante al agente. Pero en la relación víctimaEstado, la responsabilidad objetiva es la medida que se impone.

Tales cuestiones reclaman la determinación, precisamente, de cuáles son los elementos necesarios para configurar responsabilidad objetiva del Estado por omisión.

\section{Requisitos configuradores de la responsabilidad objetiva del Estado por omisión y la prescindibilidad de la "posibilidad material de actuar"}

De la inmersión emprendida en las diversas teorías acerca de la responsabilidad civil del Estado, especialmente aquellas desarrolladas en Francia, fue posible inferir que en el ordenamiento jurídico brasileño el Estado se encuentra sometido a una sistemática homogénea de responsabilización decurrente del comportamiento ineficiente, sea comisivo (mal funcionamiento) u omisivo (no funciona o funciona tardíamente): la responsabilidad objetiva. Dicho esto, es esencial en este momento verificar cuáles son los elementos que componen ese mecanismo de apuración de la responsabilidad extraído del sistema jurídico.

80 Bacellar Filho (2006a), p. 52. 
Hay tres requisitos necesarios para que se pueda configurar la responsabilidad por la violación del principio de la eficiencia: (a) Incumplimiento de un deber jurídico concreto de actuar (omisión) o cumplimiento precario (acción) por parte del Estado o de quien lo represente; (b) Ocurrencia de daño al ciudadano; (c) Nexo de causalidad entre el comportamiento estatal y el perjuicio sufrido.

(a) Incumplimiento de un deber jurídico concreto de actuar (omisión) o cumplimiento precario (acción) por parte del Estado o de quien lo represente:

Un comportamiento ineficiente podrá ser comisivo u omisivo. Si la acción practicada es diferente de aquella prevista legalmente, habrá entonces el incumplimiento comisivo de la norma, no omisivo. Conforme observa Emerson Gabardo: "La acción ineficiente no implica la existencia de la necesaria inercia característica de la omisión. Ni todo acto ineficiente es realizado por omisión. Y tampoco toda abstención de cumplimiento del deber es caso de ineficiencia". ${ }^{81}$

El Estado será ineficiente cuando su comportamiento fuera: (i) omiso, por incumplir un deber de actuar encomendado a la Administración Pública; (ii) moroso, por no respetar el deber de celeridad; (iii) exageradamente formalista, por obstaculizar una actuación ágil y fluida, marcada por la sencillez y objetividad; (iv) perdulario, por ignorar el deber de optimización de los recursos para el alcance de los mejores resultados; (v) improductivo, por violar el deber de realización de los objetivos previstos por la ley para el efectivo logro del interés público. ${ }^{82} \mathrm{En}$ la primera hipótesis, se trata de omisión, mientras que en las otras la ineficiencia constituirá una acción. Por acción u omisión, la conducta ineficiente resulta en responsabilidad objetiva.

En cuanto a los daños causados por la acción, este primer elemento -(a) el comportamiento ineficiente- estará configurado cuando el Estado (o quien lo represente) deje de atender alguno de los despliegues del principio de la eficiencia administrativa. ${ }^{83}$ Tratándose de omisión, es necesario que haya el incumplimiento de un deber específico, concreto, impuesto por el ordenamiento jurídico al Estado.

La doctrina española comúnmente afirma que para configurarse una omisión jurídicamente relevante, se necesitan dos elementos: (i) un material -la constatación, en el mundo de los hechos, de una situación de pasividad o inercia de la

81 GABARDO (2003), pp. 284-285.

82 Gabardo y Hachem (2010), p. 283.

83 Sobre el contenido jurídico del principio de eficiencia administrativa, previsto en el art. 37, de la Constitución brasileña de 1988, ver, por todos: GABARDO (2002). 
Administración; y (ii) un formal -la infracción de un deber legal o constitucional de actuar, que hace antijurídica la omisión material-. ${ }^{84}$ Si no hay deber legal o constitucional de actuar (elemento formal), no hay omisión y por consiguiente no hay responsabilidad. Esto ocurre no porque de la conducta omisiva no puedan surgir efectos jurídicos de forma directa, sino porque en este caso la omisión es irrelevante bajo el punto de vista del Derecho.

Cabe señalar que no siempre la omisión se configurará como un incumplimiento del deber de impedir una acción externa. ${ }^{85}$ Como subraya Weida Zancaner: "Puede la omisión llegar a ser causa eficiente del daño". ${ }^{86}$ Hay casos en que el deber de acción es distinto del deber de impedir acto de tercero o hecho exterior. Es el caso, ejemplificado por Emerson Gabardo, de omisión del Estado en cumplir un orden constitucional específico, como la obligación de realizar la revisión general anual de los empleados públicos (artículo 37, X, de la Constitución brasileña ${ }^{87}$ ). ${ }^{88}$ El propio incumplimiento del ente en promulgar la ley revisando la remuneración de los empleados públicos se configura como la causa dañina, ocasionadora de un perjuicio indemnizable. Lo mismo ocurre en relación con el deber de prestación de servicios públicos para la realización del derecho fundamental a la educación, por ejemplo (artículos $6^{\circ}$ y 205 de la Constitución brasileña ${ }^{89}$ ): la ausencia de la prestación del servicio por inexistencia de vacante en escuela pública constituye, por sí mismo, la omisión causante del daño. Por lo tanto, para configurarse una omisión apta para originar un daño indemnizable no es necesario que se trate del incumplimiento de un deber estatal de impedir un evento externo.

84 Puente (2002), p. 62.

85 Mello (2010a), p. 997.

86 ZANCANER (1981), p. 62.

87 Constitución de la República Federativa de Brasil: "Art. 37. La Administración Pública, directa, indirecta o institucional de cualquiera de los Poderes de la Unión, de los Estados, del Distrito Federal y de los Municipios obedecerá a los principios de legalidad, impersonalidad, moralidad, y también a lo siguiente: (...) $\mathrm{X}$ - la remuneración de los servidores públicos y el sueldo de que trata el $\$ 4^{\circ}$ del art. 39 solamente podrán ser fijados o alterados por ley específica, observada la iniciativa privativa en cada caso, asegurada la revisión general anual, siempre en la misma fecha y sin distinción de índices".

88 Gabardo (2003), p. 280.

89 Constitución de la República Federativa de Brasil: "Art. 60. Son derechos sociales la educación, la salud, la alimentación, el trabajo, la vivienda, el descanso, la seguridad, la jubilación, la protección de la maternidad y de la infancia, la asistencia a los desamparados, en la forma de esta Constitución”.

Constitución de la República Federativa de Brasil: "Art. 205. La educación, derecho de todos y deber del Estado y de la familia, será promovida e incentivada con la colaboración de la sociedad, visando el pleno desenvolvimiento de la persona, su preparación para el ejercicio de la ciudadanía y su calificación para el trabajo". 


\section{(b) Ocurrencia de daño al ciudadano:}

Para que se configure el deber de indemnizar, es necesario que el ciudadano sufra un daño concreto, de naturaleza material o moral. En materia de responsabilidad pública por acción, es irrelevante la licitud o ilicitud de la conducta estatal. Lo que pasa es que cuando se trata de omisión, como se ha dicho anteriormente, ella será jurídicamente relevante solamente en las hipótesis en que la inactividad estatal configure un incumplimiento de un deber jurídico. Por ello, tratándose de omisión, aunque no se exija la ocurrencia de negligencia, imprudencia o impericia, será esencial la antijuridicidad de la inercia para dar lugar a la responsabilidad.

Sin embargo, la sola contrariedad de la omisión al Derecho no es suficiente para originar el deber de indemnizar. Además de la ilicitud o inconstitucionalidad de la conducta, el ciudadano tiene que comprobar la existencia de un daño concreto, específico, por él sufrido.

(c) Nexo de causalidad entre el comportamiento estatal y el perjuicio sufrido:

Además de los dos elementos antes mencionados, es menester la comprobación de que el daño experimentado fue una consecuencia de la conducta estatal. Por ejemplo, la falencia de una empresa que había requerido la renovación de una licencia ambiental para explorar una actividad económica, sin tener su pedido apreciado y deferido por la Administración dentro del plazo legalmente establecido, puede ser demostrada como un efecto directo de la abstención estatal, cuando la imposibilidad de seguir explorando su actividad, originada por no resolución de su requerimiento administrativo, impida dar cumplimiento a sus obligaciones con acreedores.

En este punto, tal vez, resida la principal causa de la disputa teórica respecto de la naturaleza objetiva o subjetiva de la responsabilidad civil del Estado: hay, muchas veces, una confusión de la doctrina entre dos categorías jurídicas distintas: el nexo de causalidad y la culpa. Cuando se dice, por ejemplo, que en razón del supuesto carácter subjetivo de la responsabilidad por omisión el Estado no tiene el deber de indemnizar al ciudadano que sufrió un accidente causado por un evento irresistible de la naturaleza, pues aunque se haya omitido él no tenía el deber de evitar el daño, lo que en verdad se está afirmando es que no había nexo causal entre la abstención y el perjuicio. La causa eficiente del daño fue el factor externo y no la omisión estatal, porque no existía el deber jurídico de evitarlo. La razón de la no configuración de responsabilidad en este caso no es la ausencia de culpa, sino la inexistencia de nexo de causalidad.

Hay que separar, como en general se hace en el Derecho Penal, los planos de la antijuridicidad y de la culpabilidad. El primero se refiere a la contrariedad de la 
conducta al ordenamiento jurídico. El segundo consiste en la reprobabilidad del comportamiento, por exigirse conducta diversa. Tratándose de responsabilidad civil del Estado por omisión, es necesaria la ocurrencia de antijuridicidad-contrariedad al sistema normativo-, pero es irrelevante jurídicamente la culpabilidad -existencia de comportamiento reprobable-. Un ejemplo específico sobre el tema de los derechos fundamentales sociales puede ilustrar lo que se está afirmando.

En Brasil la Constitución asegura a los servidores públicos el derecho a la huelga, en el art. 37, VII90. Aunque fuera necesaria su reglamentación legislativa, que hasta ahora no fue promulgada, el Supremo Tribunal Federal definió los límites para su ejercicio, con carácter general y abstracto, en algunos fallos, que disciplinan la materia mientras la ley específica no esté aprobada. Pero la misma Constitución garantiza a los ciudadanos el derecho a un servicio público adecuado (art. 175, párrafo único, IV91). En los casos en que los servidores de un hospital público estuvieren ejerciendo su derecho a la huelga dentro de las especificaciones trazadas por la Corte Suprema y que se produzcan daños a la salud de determinados ciudadanos porque no había médicos suficientes para atenderlos -destáquese: aunque el límite exigido de permanencia de servidores sea cumplido-, ¿ ‘habrá el deber de indemnizar?

Si adoptada la teoría subjetiva, la respuesta sería no: no hubo culpa de la Administración, pues los servidores públicos estaban ejerciendo regularmente un derecho constitucional. No hubo negligencia, imprudencia o impericia. Si adoptada la teoría objetiva, defendida en este estudio, se contestaría a la cuestión de manera afirmativa: habrá responsabilidad, toda vez que, no obstante la inexistencia de culpabilidad -exigibilidad de conducta diversa-, hubo antijuridicidad-incumplimiento del deber de prestar un servicio público adecuado-. Y, además, se ocasionó un perjuicio derivado de la omisión estatal, configurando el nexo causal. La antijuridicidad no está en el ejercicio del derecho a la huelga, sino en la ausencia de prestación eficiente del servicio público de salud. Existe, en este caso, un nexo de causalidad entre el mencionado incumplimiento de la

90 Constitución de la República Federativa de Brasil: “Art. 37. La Administración Pública, directa, indirecta o institucional de cualquiera de los Poderes de la Unión, de los Estados, del Distrito Federal y de los Municipios obedecerá a los principios de legalidad, impersonalidad, moralidad, y también a lo siguiente: (...) VII - el derecho a la huelga será ejercido en los términos y límites definidos en ley específica”.

91 Constitución de la República Federativa de Brasil: “Art. 175. Incumbe al Poder Público, en la forma de la ley, directamente o bajo régimen de concesión o permisión, siempre a través de licitación, la prestación de servicios públicos. Párrafo único. La ley dispondrá sobre: (...) IV - la obligación de mantener servicio adecuado". 
Constitución y el daño a la salud de los ciudadanos afectados por la violación de la Ley Fundamental.

Fuera de los tres requisitos -(a) (b) y (c)- ya referidos, la doctrina, especialmente en España y Argentina, tiene la costumbre de añadir un cuarto elemento para la configuración de la responsabilidad en los casos de omisión: (d) la posibilidad material de actuar. ${ }^{92}$ Para esta corriente, el Estado debe gozar de las condiciones necesarias -financieras, jurídicas, fácticas- para cumplir adecuadamente con el deber emanado del sistema normativo; de lo contrario, no podrá ser responsabilizado.

La inclusión de este requisito como necesario a la configuración de la responsabilidad significa retomar el elemento "culpa", encarando el régimen de responsabilización como subjetivo. Esto porque, en caso de que el Estado no haya podido actuar, no tuvo culpa en relación con el daño, y luego estaría justificada la exoneración de su deber de reparar el daño. En esta línea, se estaría aceptando la "reserva del posible" 93 como causa exonerativa de las obligaciones del Estado: el deber de actuar sólo se impondría cuando las condiciones financieras y fácticas permitieren la actuación del Estado.

Aceptar este requisito importaría admitir la responsabilidad subjetiva, ya que objetivar la responsabilidad implica tornar irrelevante la existencia de culpa o dolo, o sea, es desconsiderar si hay negligencia, impericia o imprudencia en la conducta. Y tener en cuenta la posibilidad material de actuar significa analizar si, en el caso de omisión, hubo negligencia (si el Estado podría haber actuado y no actuó, fue negligente).

No se puede concordar con tal exigencia, sea como requisito para configurar la responsabilidad del Estado en casos de omisión, sea para utilizarlo como excluyente de la responsabilidad, como parece ser la posición de Juarez Freitas94 y Maria Sylvia Zanella Di Pietro. ${ }^{95}$ Con el respeto debido a los ilustres doctrinadores, el entendimiento no merece concordancia, pues parece acoger la "reserva del posible", como obstáculo a la efectuación de los derechos fundamentales. Siguiendo este raciocinio, se concluiría que los derechos fundamentales deben ser realizados por el Poder Público en la medida de lo financieramente posible, de suerte que, si no hubiere recursos disponibles, se justifica la violación de dichos derechos por omisión estatal. Es decir: el Estado sólo estaría obligado a atender

92 Puente (2002), p. 107; Salomoni (2006), p. 119.

93 Sobre el tema, ver Pereira (2009).

94 Freitas (2006), p. 178.

95 Pietro (2010), p. 655. 
las imposiciones constitucionales relativas a los derechos fundamentales si eso no comprometiera demasiado los cofres públicos.

La idea resultaría en admitir, por ejemplo, que los hospitales públicos no están sujetos al atendimiento del derecho fundamental a la salud -ignorando la literalidad de los artículos 6 y 195 de la Constitución brasileña- cuando la demanda es excesiva, ni reparar los daños decurrentes de esta omisión. Se olvida, por lo tanto, del deber de diligencia en la realización optimizada y maximizada de los mandatos constitucionales, desdoblamiento inequívoco del principio constitucional de la eficiencia administrativa. ${ }^{96}$ Así, hay que concordar con Romeu Felipe Bacellar Filho, para quien la "reserva del posible" no puede encontrar acogida en el ordenamiento jurídico brasileño, siquiera como excluyente o atenuante de la responsabilidad civil del Estado en los casos de omisión. ${ }^{97}$

Comprender de forma diversa conduciría a la negación del carácter normativo del principio constitucional de la eficiencia administrativa, lo cual impone al Estado la obligación de realizar fielmente el interés público plasmado en el Derecho positivo, mayormente en lo que toca a la efectivación de los derechos fundamentales. ${ }^{98}$ La materialización de dichos derechos a través de la actividad administrativa retrata la exigencia no solamente del principio de la eficiencia (artículo 37, de la Constitución brasileña), sino también de la aplicabilidad inmediata de los derechos fundamentales, en virtud del artículo $5^{\circ}, \$ 1^{\circ}$ de la Constitución ${ }^{99}$. Este dispositivo, combinado con el principio de eficiencia, tiene el propósito de obligar a la Administración Pública a promover con la máxima presteza los servicios necesarios para satisfacer las necesidades más esenciales del ciudadano, imprescindibles para la concretización del principio fundamento de la República Federativa de Brasil: la dignidad de la persona humana (artículo 1º, III, CF). ${ }^{100}$

\section{BiBLIOGRAFIA CITADA}

Alexy, Robert (2007): Teoría de los derechos fundamentales. 2a ed. (Madrid, Centro de Estudios Políticos y Constitucionales).

96 Gabardo y Hachem (2010), pp. 255-256.

97 Bacellar Filho (2007), p. 243.

98 Cfr. Finger (2003), pp. 142-165.

99 Constitución de la República Federativa de Brasil: “Art. $5^{\circ}$. (...) $\$ 1^{\circ}$. Las normas definidoras de derechos y garantías fundamentales tienen aplicación inmediata”.

100 Sobre el tema, ver НАСнем (2008), pp. 59-71. 
Bacellar Filho, Romeu Felipe (2007): Direito Administrativo e o Novo Código Civil (Belo Horizonte, Fórum).

(2006a): "Responsabilidad civil del Estado por omisión”, en Revista argentina del régimen de la administración pública, v. 326, pp. 45-52.

(2006b): "Responsabilidade civil da Administração Pública - aspectos relevantes. A Constituição Federal de 1988. A questão da omissão. Uma visão a partir da doutrina e da jurisprudência brasileiras”, en Juarez Freitas (Org.), Responsabilidade Civil do Estado (São Paulo, Malheiros), pp. 293-336.

(2000): "Responsabilidade civil extracontratual das pessoas jurídicas de direito privado prestadoras de serviços públicos", en Interesse Público (abr. jun, No 6), pp. 11-47.

Bacellar Filho, Romeu Felipe; Gabardo, Emerson; Hachem, Daniel Wunder (Coords.) (2011): Globalização, Direitos Fundamentais e Direito Administrativo: novas perspectivas para o desenvolvimento econômico e socioambiental (Belo Horizonte, Fórum).

Barcellos, Ana Paula de (2011): A eficácia jurídica dos princípios constitucionais: o princípio da dignidade da pessoa humana. $3^{\mathrm{a}} \mathrm{ed}$. (Rio de Janeiro, Renovar). BARROSO, Luís Roberto (2008): "Da falta de efetividade à judicialização excessiva: direito à saúde, fornecimento gratuito de medicamentos e parâmetros para a atuação judicial”, en Cláudio Pereira de Souza Neto; Daniel Sarmento (Coords.), Direitos Sociais: Fundamentos, Judicialização e Direitos Sociais em Espécie (Rio de Janeiro, Lumen Juris), pp. 875-903.

Bittencourt Neto, Eurico (2010): O direito ao mínimo para uma existência digna (Porto Alegre, Livraria do Advogado).

Carneiro, Paulo Cezar Pinheiro (1999): Acesso à justiça: juizados especiais e ação civil pública (Rio de Janeiro, Forense).

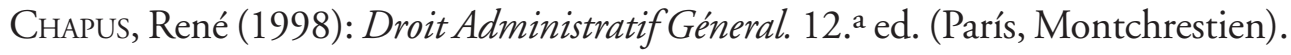
ClÈve, Clèmerson Merlin (2011a): "A eficácia dos direitos fundamentais sociais", en Romeu Felipe Bacellar Filho; Daniel Wunder Hachem (Coords.). Globalização, Direitos Fundamentais e Direito Administrativo: novas perspectivas para o desenvolvimento econômico e socioambiental (Belo Horizonte, Fórum). pp. 95-108.

(2011b): Atividade legislativa do Poder Executivo. $3^{\mathrm{a}}$ ed. (São Paulo, Revista dos Tribunais). 
Di PIETro, Maria Sylvia Zanella (2010): Direito Administrativo. 23a ed. (São Paulo, Atlas).

Duguit, Léon (1913): Les transformations du droit public (París, Librairie Armand Colin).

Figueiredo, Lúcia Valle (2008): Curso de Direito Administrativo. 9a ed. (São Paulo, Malheiros).

Finger, Ana Cláudia (2003): "Serviço Público: Um Instrumento de Concretização de Direitos Fundamentais”, en A\&C - Revista de Direito Administrativo \& Constitucional (n. 12), pp. 142-165.

FreITAS, Juarez (2006): "Responsabilidade civil do Estado e o princípio da proporcionalidade: vedação de excesso e de inoperância", en Juarez Freitas (Org.), Responsabilidade Civil do Estado (São Paulo, Malheiros), pp. 170-197.

Gabardo, Emerson (2002): Princípio constitucional da eficiência administrativa (São Paulo, Dialética).

(2003): "Responsabilidade objetiva do Estado em face dos princípios da eficiência e da boa-fé", en Luciano Ferraz; Fabrício Motta (Orgs.), Direito Público Moderno (Belo Horizonte, Del Rey), pp. 259-298.

Gabardo, Emerson; Hachem, Daniel Wunder (2010): "Responsabilidade civil do Estado, faute du service e o princípio constitucional da eficiência administrativa”, en Guerra, Alexandre D. de Mello; Pires, Luis Manuel Fonseca; Benacchio, Marcelo (Orgs.), Responsabilidade Civil do Estado: desafios contemporâneos (São Paulo, Quartier Latin), pp. 240-292.

HaChem, Daniel Wunder (2008): "A responsabilidade civil do Estado frente às omissões estatais que ensejam violação à dignidade da pessoa humana", en A 6 C - Revista de Direito Administrativo \& Constitucional (n. 34), pp. 59-71. (2012): Mandado de injunção e direitos fundamentais: uma construção à luz da transição do Estado Legislativo ao Estado Constitucional (Belo Horizonte, Fórum).

Long, Marceau; Weil, Prosper; Braibant, Guy; Devolvé, Pierre; Genevois, Bruno (2007): Les grands arrêts de la jurisprudence administrative. $16^{\mathrm{a}}$ ed. (París, Dalloz).

MARIENHOFF, Miguel S. (2001): Responsabilidad extracontractual del Estado por las consecuencias de su actitud "omisiva" en el ámbito del derecho público (Buenos Aires, Abeledo Perrot).

Maurício JR., Alceu (2009): A revisão judicial das escolhas orçamentárias: a intervenção judicial em políticas públicas (Belo Horizonte, Fórum). 
Mello, Celso Antônio Bandeira de (2010a): Curso de Direito Administrativo. 27a ed. (São Paulo, Malheiros). Paulo, Malheiros).

Mello, Oswaldo Aranha Bandeira de (1969): Principios gerais de direito administrativo (Rio de Janeiro, Forense), v. II.

Morand-Deviller, Jacqueline (1999): Cours de Droit Administratif. 6a ed. (París, Montchrestien).

NovaIs, Jorge Reis (2010): Direitos sociais: teoria jurídica dos direitos sociais enquanto direitos fundamentais (Coimbra: Coimbra Editora).

Nunes, António Avelās; Coutinho, Jacinto Nelson de Miranda (Org.) (2004): Diálogos Constitucionais: Brasil/Portugal (Rio de Janeiro, Renovar).

PAILLET, Michel (1980): La faute du service public en droit administratif français (París, LGDJ).

Pereira, Ana Lúcia Pretto (2009): A reserva do possivel na jurisdição constitucional brasileira: entre o constitucionalismo e democracia (Curitiba, Dissertação (Mestrado) - Setor de Ciencias Jurídicas, Universidade Federal do Paraná).

Puente, Marcos Gómez (2002): La inactividad de la Administración. $3^{\mathrm{a}}$ ed. (Navarra, Aranzadi).

R7 (2011). "Após ser atropelada, mulher de 27 anos morre à espera de vaga em hospital no Rio" (fecha de consulta: 17 de mayo de 2012). Disponible en http://noticias.r7.com/rio-de-janeiro/noticias/jovem-morre-esperando-vagaem-hospital-no-rio-20110707.html.

Richer, Laurent (1978): La faute du service public dans la jurisprudence du Conseil d'État (París, Económica).

Salomoni, Jorge Luis (2006): "La responsabilidad del Estado por omisión en la República Argentina”, en Juarez Freitas (Org.), Responsabilidade Civil do Estado (São Paulo, Malheiros), pp. 103-135.

SARLET, Ingo Wolfgang (2010): A eficácia dos direitos fundamentais: uma teoria geral dos direitos fundamentais na perspectiva constitucional. 10a ed. (Porto Alegre, Livraria do Advogado).

Souza Neto, Cláudio Pereira de (2008a): "A justiciabilidade dos direitos sociais: críticas e parâmetros", en Daniel Sarmento (Coords.), Direitos sociais: fundamentos, judicialização e direitos sociais em espécie (Rio de Janeiro, Lumen Juris). 
Souza Neto, Cláudio Pereira de; Sarmento, Daniel (Coords.) (2008b): Direitos Sociais: Fundamentos, Judicialização e Direitos Sociais em Espécie (Rio de Janeiro, Lumen Juris).

Torres, Ricardo Lobo (2003): "A jusfundamentalidade dos direitos sociais", en Revista de Direito da Associação dos Procuradores do Novo Estado do Rio de Janeiro (v. 12), pp. 349-374.

(2009): O direito ao minimo existencial (Rio de Janeiro, Renovar). (2004): "O Mínimo Existencial, os Direitos Sociais e a Reserva do Possível”, en António Avelās Nunes; Jacinto Nelson de Miranda Coutinho (Org.), Diálogos Constitucionais: Brasil/Portugal (Rio de Janeiro, Renovar), pp. 447-471.

Vedel, Georges; Devolvé, Pierre (1992): Droit Administratif. 12a ed. (París, PUF). Waline, Marcel (1959): Traité de Droit Administratif. $8^{\mathrm{a}} \mathrm{ed}$. (Paris, Sirey).

ZANCANER, Weida (1981): Da responsabilidade extracontratual da Administração Pública (São Paulo, Revista dos Tribunais).

Zero Hora (2011): "Idoso morre em Viamão à espera de leito em UTI" (fecha de consulta: 17 de mayo de 2012). Disponible en: http://zerohora.clicrbs. com.br/rs/geral/noticia/2011/09/idoso-morre-em-viamao-a-espera-de-leito -em-uti-3491937.html

\section{Jurisprudencia citada}

BRASIL (1996): Superior Tribunal de Justiça. Recurso Ordinário no Mandado de Segurança No 6.564/RS, Rel. Ministro Demócrito Reinaldo, Primeira Turma, julgado em 23.05.1996, DJ 17.06.1996.

Brasil (1997): Supremo Tribunal Federal. Medida Cautelar na Petição No 1246,

Presidente Ministro Sepúlveda Pertence, Decisão Proferida pelo Ministro Celso de Mello, julgado em 31.01.1997, publicado em DJ 13.02.1997.

BRASIL (1998): Tribunal de Justiça do Estado do Rio de Janeiro. Mandado de Segurança No 220/98, Rel. Del. Antonio Lindberg Montenegro, julgado em 17. 12.1998 .

BRASIl (2007): Superior Tribunal de Justiça. Recurso Especial No 811.608/ RS, Rel. Ministro Luiz Fux, Primeira Turma, julgado em 15.05.2007, DJ 04.06.2007.

BRASIL (2007): Supremo Tribunal Federal. Ação Direta de Inconstitucionalidade No 3768, Relatora Ministra Cármen Lúcia Antunes Rocha, Tribunal Pleno, 
julgado em 19.09.2007, DJe-131, divulgado em 25.10.2007, publicado em 26.10.2007.

BRASIL (2010): Supremo Tribunal Federal, Suspensão de Tutela Antecipada no Agravo Regimental No 175, Relator Min. Gilmar Mendes (Presidente), Tribunal Pleno, julgado em 17.03.2010, DJe-076, divulgado em 29.04.2010, publicado em 30.04.2010. 